IFN Working Paper No. 838, 2010

\title{
Optimal Transmission Regulation in an Integrated Energy Market
}

\section{Thomas P. Tangerås}




\title{
Optimal Transmission Regulation in an Integrated Energy Market*
}

\author{
Thomas P. Tangerås \\ Research Institute of Industrial Economics (IFN) \\ P.O. Box 55665, SE-102 15 Stockholm, Sweden \\ E-mail: thomas.tangeras@ifn.se \\ Homepage: www.ifn.se/thomast
}

June 1, 2010

\begin{abstract}
The capacity of the transmission network determines the extent of integration of a multinational energy market. Cross-border externalities render coordination of network maintenance and investments across countries valuable. Is it then optimal to collect powers in the hands of a single regulator? Should a common system operator manage the entire network? I show that optimal network structure depends on $(i)$ how the common regulator would balance the interests of the different member states; (ii) how the gains from market integration vary across countries; (iii) network characteristics (substitutability versus complementarity); and $(i v)$ the social cost of operator rent.

Keywords: Multi-national energy market; transmission; supranational regulation; system operation; multi-contracting.

JEL classifications: D62; D82; L51; L94.
\end{abstract}

*Many thanks to Pär Holmberg, Henrik Horn, Erik Lundin, Espen Moen, seminar participants at IFN, Stockholm University, BI Norwegian School of Management, Norwegian School of Economics and Business Administration as well as audiences at the following conferences/workshops: SNEE in Mölle, Market Design in Saltsjöbaden, NEECI in Reykjavik and Electricity Market Design in Geilo for their comments. This research was financed within the IFN research program "The Economics of Electricity Markets" (www.ifn.se/Research_Program_The_Economics_of_Electricty_Markets). 


\section{Introduction}

The European Commission (2007) views the completion of an integrated European energy market essential for ensuring competitiveness, sustainability and security of energy supply in Europe. Market integration depends crucially on the transmission network connecting the member states being capable of reliably transporting energy from power plants in one country to consumers in another. Increasing shares of solar and wind energy place additional requirements on the grid as production and energy flows become more volatile. The transmission network is a natural monopoly because it is too expensive to build competing networks. Absent a competitive pressure, establishing and maintaining an efficient multi-national transmission network boils down to implementing optimal multi-national regulatory policies.

Most liberalized electricity markets have been deregulated one country at a time. Owing to the national scope of liberalization, also transmission regulation has been national in scope whereby national regulatory agencies govern national system operators responsible for managing the national transmission networks. The question is whether this national transmission governance structure is optimal any longer in a multi-national energy market. ${ }^{1}$ In a multi-national energy market, improvements in grid capacity at home creates externalities abroad because energy flows and prices change across the entire market with the removal of each transmission bottleneck. With too narrow a focus on domestic effects, national regulatory agencies run the risk of ignoring the externalities abroad when devising regulatory policy for the national system operator.

Two examples from the Nordic electricity market illustrate the cross-border externalities of transmission capacity. The Nordic electricity market was the world's first multi-national liberalized electricity market and now spans Denmark, Finland, Norway and Sweden. In the spring of 2008, main transmission lines connecting southern Norway and southern Sweden broke down on the Norwegian side, severely limiting export capacity to Sweden. One year later the connections were still not back to full capacity. According to the Norwegian regulator, the break downs were largely due to insufficient maintenance by the Norwegian system operator, Statnett. Admitting that the repairs were taking an unusually long time, Statnett emphasized that the security of supply for Norwegian consumers was never jeopardized. Meanwhile, the consumers in southern Norway had been enjoying comparatively lower electricity prices. The effects on consumers and producers in Sweden (or elsewhere) seem to have been absent from the Norwegian discussion.

In the spring of 2009, the European Commission opened proceedings against the Swedish system operator, Svenska Kraftnät, for the abuse of its dominant position as the sole provider of Swedish transmission capacity. The allegation was that Svenska Kraftnät limited exports to Denmark to alleviate domestic congestion problems stemming from excess demand in southern Sweden. By cutting the outflow of electricity, Svenska Kraftnät was able to export price increases from southern Sweden to Denmark thereby achieving the goal of a uniform electricity price

\footnotetext{
${ }^{1}$ Large countries, like the US, are divided into regional electricity markets with regional regulatory agencies and regional grid monopolies. Market integration then is a question of connecting multiple regional markets into a larger one. The theoretical framework of this paper applies to this case, too.
} 
throughout Sweden. Denmark complained that Svenska Kraftnät did not take into account the costs to the Danish consumers of the export limitations.

With the cross-border externalities in mind, would it not be better to establish a common regulatory agency responsible for the entire transmission network? Should the national system operators be merged into a single common system operator? This paper analyzes these horizontal aspects of optimal transmission network structure. The discussion of network structure has so far centered around the costs and benefits of vertical separation of transmission operation from production; see e.g. Cremer et al. (2006) for an analysis and Pollitt (2008) for an account of the arguments. For the fear that integrated utilities will discriminate against competitors and invest inadequately in their networks, the EU recommends full ownership unbundling of transmission and production assets (EU, 2009b). However important vertical structure may be, overall network performance depends crucially on the incentives induced by the regulatory policies adopted by the different member states, which is precisely the topic of this paper. The establishment of the Agency for the Cooperation of Energy Regulators, ACER, and the European Network of Transmission System Operators for Electricity, ENTSO, bears witness to the importance EU policy makers attach to cross-border coordination of regulatory policies and system operation.

I consider a two-country energy market with interconnected networks. Network reliability increases with maintenance spending in both networks. Gains from energy trade render network reliability valuable. The scope of regulation is to provide the system operator(s) with the appropriate incentives for network maintenance while minimizing maintenance cost and operator rent. First-best optimal spending occurs at the point at which the marginal benefit of network reliability equals the marginal social maintenance cost.

Two complications render network structure important for network performance. First, because the gains from energy market integration vary across countries, the member states differ in their valuation of network reliability. These asymmetries are not likely to vanish with the introduction of a common regulatory agency (CRA). The desirability of establishing a single regulator depends on how well these differences are reconciled within the CRA. Second, an informational asymmetry is the source of an agency problem between the regulator(s) and the system operator(s). The regulator has insufficient information to assess whether network performance is inferior for exogenous reasons (low productivity) or endogenous reasons (insufficient maintenance). By understating the productivity of the network, a system operator can secure itself excessive transfers relative to the cost of maintaining the network. The nature of this agency problem depends on how system operation is organized.

As optimal network structure is both a question of how many regulators and how many system operators there should be, a number of potential network structures need to be compared against one another. The Nordic electricity market exemplifies the governance structure labelled Separation in Table 1: Every member state has its own national system operator (NSO) regulated by a national regulatory agency (NRA). An advocated contender is Integration whereby the responsibility for managing the entire transmission grid lies upon a common system operator (CSO). A common regulatory agency (CRA) governs the CSO. Common regulation constitutes 
a compromise between Separation and Integration and features a set of NSOs jointly regulated by a CRA. To complete the picture, Common agency describes a situation whereby multiple national regulatory agencies independently regulate a single CSO. Although relevant in other regulated sectors such as telecommunications, Common agency does not appear to be a likely network transmission structure. Discussions of the merits of having a single system operator seem to implicitly assume a complementary coordination of regulatory policies. For example, an investigation of the desirability of a Nordic system operator concluded that national governments should then have to relinquish some (regulatory) autonomy, else interference from the national governments would create inefficiencies in system operation (EMG, 2008). I therefore skip a detailed analysis of Common agency at this stage, although one might want to consider it for the sake of completeness.

\begin{tabular}{|r|r|r|}
\hline & National regulatory agencies & Common regulatory agency \\
\hline National system operators & Separation & Common regulation \\
\hline Common system operator & Common agency & Integration \\
\hline
\end{tabular}

Table 1: A taxonomy of network governance structures

Under Separation, the two national regulatory agencies (NRAs) play a non-cooperative game against each other whereby each NRA chooses its regulatory policy to maximize national welfare given the choice of policy by the other NRA. This lack of policy coordination creates two distortions. Internalizing only the domestic gains from market integration, the NRAs provide their national system operators (NSOs) insufficient incentives for network maintenance. As a consequence, overall network reliability is too low under Separation. Second, the NSO in the country with the highest gains from trade spends too much on maintenance relative to the other NSO. This productive inefficiency arises whenever the perceived marginal benefit of network reliability differs across countries. Asymmetric information further exacerbates maintenance under-spending. Suppose an NRA wants to induce increased maintenance spending of its NSO whenever the national network is of low productivity. Due to asymmetric information between the NRA and the NSO about true productivity, the NRA cannot target spending directly towards the low-productivity network, but is forced to compensate the NSO even if the network actually is in a good shape. This spill-over effect, or informational rent, yields a virtual marginal maintenance cost in excess of the marginal social maintenance cost, which distorts maintenance spending in low productivity networks even further.

Establishing a common regulatory agency (CRA) takes care of the productive inefficiency because maintenance spending now is optimally coordinated across the network. However, the distortions in aggregate maintenance spending do not necessarily vanish with the abolishment of national regulatory agencies. Instead, the distortions may be accentuated. Assume, for example, that most of the gains from market integration fall upon one of the countries, whereas the country with the least to gain from integration holds decisive control over the CRA. The CRA then understates the marginal benefit of network reliability, providing the system operator(s) 
insufficient maintenance incentives. In this case, network reliability is so low that Separation welfare dominates Common regulation and Integration despite the productive inefficiencies under Separation. The key to establishing a well-functioning common regulatory agency is to ensure a balanced political influence across the member states. With an equal distribution of political power, no member state can exert enough influence over the regulatory policy to tilt it in one's own favour: Aggregate spending is near the social optimum, and Common regulation welfare dominates Separation.

How to organize system operation depends crucially on the characteristics of the transmission network and on the social cost of operator rent. Consider the case with two NSOs. Under the assumption of network complementarity, the marginal value of maintenance spending in one part of the network is higher, the higher is productivity in the other part of the network. Under network complementarity, the home NSO exerts a negative informational rent externality on the foreign NSO by understating the productivity of its network. The perceived marginal value of maintenance spending abroad then is understated, and the informational rent of the foreign NSO falls because informational rent is an increasing function of maintenance spending. By merging system operation into a single CSO, the regulator forces the system operators to internalize the negative rent externality through cross-subsidization, thereby reducing overall informational rent.

The superior ability of the CSO to jointly understate productivity of the entire network adds to the virtual marginal maintenance cost of low productivity networks under Integration. This extra maintenance cost tends to depress optimal maintenance spending below the optimal level under Common regulation for the case when both national networks are of low productivity. The downward incentive distortion is weaker the lower is the social cost of operator rent. However, under network substitutability, low productivity in one part of the network raises the marginal value of maintenance spending in the other part of the network. This substitution effect pulls in favour of higher maintenance spending. The substitution effect dominates the cost effect whenever the social cost of operator rent is low. In this case, a CSO understating productivity in one part of its network exerts a positive informational rent externality on the other part of the network. In the presence of positive informational rent externalities, the regulator optimally splits system operation between a set of national system operators to mitigate the exercise of agency power.

Specifically, this paper contributes to the understanding of network regulation in multinational energy markets by studying the costs and benefits of centralized regulation and of merging system operation. This is the first integrated study of these horizontal aspects of network regulation, as far as I know. The focus has so far been on vertical separation of transmission and production.

More generally, I contribute to the literature on multi-contracting. Multi-contracting describes a situation where one or more principals contract with one or more agents. The present paper addresses the normative aspect of multi-contracting by analyzing the socially optimal contract structure. In a unified framework, I study the welfare implications of changing the number of principals (regulators) as well as the number of agents (system operators). The ex- 
isting literature is more partial in considering either the optimal number of agents assuming a single principal (see Armstrong and Sappington (2007) for a survey), or analyzing the optimal number of principals assuming a single agent (see Martimort (2007) for a survey of such common agency models). The finding that more principals as well as more agents sometimes are better than a single principal and a single agent vindicates a broader perspective. In the present model, Separation welfare dominates Integration whenever a country with little to gain from market integration would possess a dominating influence over the common regulatory agency and there are positive informational rent externalities.

A benevolent common regulatory agency which can commit to complete long-term contracts can always replicate any contracts implemented by the national regulatory agencies and can potentially do better. Centralized regulation is always optimal in this case. Conversely, decentralized regulation can be optimal only if $(i)$ the CRA is not benevolent; (ii) has commitment problems or (iii) there are problems of contractual incompleteness at the centralized level. The present paper explores the first, political economy motive by allowing individual countries to exercise political influence over the common regulatory agency. ${ }^{2}$ The basic trade-off between centralized and decentralized regulation in this setting is between internalizing cross-border externalities of network reliability versus tailoring regulatory policies to each individual country reflecting differences in how they value network reliability. This externality/bias trade-off is classical in studies of political integration and dates back at least to Oates (1972). Ellingsen (1998) early on noted how asymmetric gains from integration favoured decentralization, a result which also appears in the present context. The importance of political balance for the desirability of centralization has gone relatively unnoticed as far as I can see (although the result is straightforward) - possibly because most models assume majority voting. Laffont and Pouyet (2003) is an exception. They study a model of multi-national procurement where political distortions arise from a tension between shareholders and non-shareholders. The centralized buyer places less weight on consumer surplus than firm rent if shareholders are in majority, but cares nothing about firm rent if shareholders are in minority. Opposite to this paper, centralized procurement welfare dominates decentralized procurement if and only if influence is asymmetrically distributed between shareholders and non-shareholders. This result can be traced to a peculiar specification of the objective function of the centralized buyer in the model: Under shareholder majority the weight of consumer surplus is higher the larger is shareholder majority. Consumer surplus and firm rent have near equal weights in the limit when almost everybody is a shareholder, in which case the centralized buyer acts almost as the benevolent social planner.

A complicating factor in analysing political integration of regulation lies in characterizing the equilibria of the game played by independent regulators. A multi-principal Revelation Principle greatly facilitates the analysis of Separation in the present setting setting. Under the plausible

\footnotetext{
${ }^{2}$ Olsen and Torsvik (1993) analyse limited commitment. They show that decentralized regulation can mitigate dynamic inefficiencies stemming from post-contractual exploitation by the centralized regulator.

Under complete contracting framework, and all necessary policy coordination takes place at the level of regulation. While a fitting description of capacity regulation, the system operator performs complicated tasks, such a balancing energy supply, which are not completely contractable. Multi-national energy markets require detailed coordination of cross-border system operation. Contractual incompleteness and optimal delegation in multi-national energy markets are interesting topics for future research.
} 
assumption of transparent regulation, I can without loss of generality constrain attention to direct and incentive compatible regulatory contracts, and there is a unique equilibrium in the game with multiple principals and multiple agents. Under the standard assumption of "opaque" regulation, the set of equilibria could potentially be very large (Yamashita, 2010), and the restriction to direct and incentive compatible contracts might come at a loss in generality (Attar et al., 2010).

This paper emphasizes the role of informational rent externalities in determining the optimal number of system operators. Dana (1993) is the first to emphasize the importance of informational rent externalities for the optimal market structure of a regulated industry. $\mathrm{He}$ focuses exclusively on negative rent externalities as a motivation for granting monopoly rights. Serevinov (2008) studies optimal organization of production in a model with a single principal and two agents. He shows that the optimal mode of organization (number of agents) depends on whether the value of information is superadditive or subadditive, which here corresponds to positive versus negative informational rent externalities. Serevinov (2008) establishes the link between the degree of substitutability/complementarity of inputs and additivity. The present paper extends Serevinov (2008) by studying also the optimal number of principals. It further complements his analysis by linking informational externalities to the social cost of informational rent.

\section{The Model}

Two countries, indexed by $i \neq j \in\{1,2\}$, distribute energy through interconnected national transmission networks. The union of the two national networks defines the common network. Interconnection enables energy trade between the two countries. Denote by $S_{i}^{I}$ the sum of producer and consumer surplus in country $i$ if the common network runs at full capacity, in which case the market is integrated, and by $S_{i}^{A}$ if the common network operates at reduced capacity. Market integration is beneficial to both countries, $\triangle S_{i}=S_{i}^{I}-S_{i}^{A}>0, i=1,2$, but the gains from trade might be asymmetrically distributed: $\triangle S_{1} \neq \triangle S_{2}$ in general. There are two reasons why both countries might benefit from integration. Increased trade improves welfare in both countries under imperfect competition in both national markets. Second, improved network capacity leads to a better utilization of total generation capacity and therefore lower aggregate production costs. Both countries profit from integration if these cost reductions are evenly distributed across the countries. ${ }^{3}$

Network reliability equals the probability $P(q)$ that the common network runs at full capacity and depends on the quality $q=\left(q_{1}, q_{2}\right)$ of the national networks. Network reliability is symmetric and an increasing and concave function of quality: $P_{i}^{\prime}>0, P_{i i}^{\prime \prime}<0, P_{11}^{\prime \prime} P_{22}^{\prime \prime} \geq P_{12}^{\prime \prime} P_{21}^{\prime \prime}$ for all $q$, where $P_{i}^{\prime}=\partial P / \partial q_{i}, P_{i i}^{\prime \prime}=\partial^{2} P / \partial q_{i}^{2}$ and $P_{i j}^{\prime \prime}=\partial^{2} P / \partial q_{i} \partial q_{j}$. Under network complementarity, marginal network reliability is increasing in the quality of the other part of the network: $P_{i j}^{\prime \prime}>0$ for all $q$. Conversely, marginal network reliability is decreasing in the quality of the other part

\footnotetext{
${ }^{3}$ Auriol and Biancini (2009) analyse the welfare implications of market integration when firms are subject to regulation.
} 
of the network, $P_{i j}^{\prime \prime}<0$ for all $q$, under network substitutability.

Network quality is the product of the exogenous productivity $\beta_{i} \in\{\underline{\beta}, \bar{\beta}\}$ of network $i$ and the resources $m_{i} \geq 0$ spent on maintaining network $i$ : $q_{i}=\beta_{i} m_{i}, i=1,2$. I assume that the quality $q_{i}$ of network $i$ is directly observable and contractible, but never its two components $\beta_{i}$ and $m_{i}$. Productivity in network $i$ is low $\left(\beta_{i}=\underline{\beta}>0\right)$ with probability $1-v$ and high $\left(\beta_{i}=\bar{\beta}>\underline{\beta}\right)$ with probability $v$. With this (common knowledge) stochastic structure, productivity $\beta=\left(\beta_{1}, \beta_{2}\right)$ is stochastically independent across the two networks.

Depending on the network governance structure, either a common system operator (CSO) runs the entire common network or two national system operators (NSOs) run one national network each. Either way, the system operator receives a transfer $t_{i}$ for operating network $i$ and obtains the rent $u_{i}=t_{i}-\psi\left(m_{i}\right)$ by devoting $m_{i}$ resources on the maintenance of network $i$, where $\psi(\cdot)$ is the unobservable maintenance cost, which is increasing and convex: $\psi^{\prime}(0)=0$, $\psi^{\prime \prime}>0$ and $\psi^{\prime \prime \prime} \geq 0 .^{4}$

Ex post social welfare equals the expected gains from trade plus operator rent minus the social cost of transfers:

$$
P(q)\left(\triangle S_{1}+\triangle S_{2}\right)+\sum_{i=1,2}\left(u_{i}-(1+\lambda) t_{i}\right),
$$

where $\lambda>0$ is the shadow price of public funds and the same in both countries. Regulation here affects the expected gains of trade only through its effect on network reliability. There is no reason why network structure as such should have any direct effect on the gains of trade $\triangle S_{1}$ and $\triangle S_{2}$. If operator revenues accrued from user fees instead of being tax financed transfers as in the present model, regulation would have a direct effect on the gains from trade. User fees would complicate the analysis technically without adding much in terms of qualitative insights; see, e.g., Chapter 2 in Laffont and Tirole (1993) for an analysis of the analogy between tax-based and user-based revenues.

The timing is as follows: Nature draws $\beta$. NSO $i$ learns $\beta_{i}$, but does not know more about $\beta_{j}$ than the regulator(s). The CSO learns the entire productivity vector $\beta$. The regulator(s) commit(s) to direct regulatory contract(s), which consist of a regulatory policy $\mathbf{q}_{i}=\left(\bar{q}_{i}, \widehat{q}_{i}, \widetilde{q}_{i}, \underline{q}_{i}\right)$ and a transfer policy $\mathbf{t}_{i}=\left(\bar{t}_{i}, \widehat{t}_{i}, \widetilde{t}_{i}, \underline{t}_{i}\right)$ for each network $i=1,2$. Upon observing the regulatory contracts $\left(\mathbf{q}_{1}, \mathbf{t}_{1}\right)$ and $\left(\mathbf{q}_{2}, \mathbf{t}_{2}\right)$, each NSO, alternatively the CSO, decides whether to accept the regulatory contract or refuse. ${ }^{5}$ A system operator who turns down the contract receives reservation utility 0 . If they both accept (I assume that this is always socially optimal), the regulated quality of network $i$ is $\bar{q}_{i}$ and the associated transfer to network $i$ is $\bar{t}_{i}$ if both networks report high productivity and $\underline{q}_{i}$ versus $\underline{t}_{i}$ if they both report low productivity. In case of dissimilar productivity reports $\left(\beta_{i}=\bar{\beta}>\underline{\beta}=\beta_{j}\right)$, the quality/transfer pair equals $\left(\widehat{q}_{i}, \widehat{t}_{i}\right)$ to the high

\footnotetext{
${ }^{4}$ The model is cast in terms of network reliability and maintenance spending. An alternative interpretation would be to view $P$ as overall network capacity, $m_{i}$ as real capacity investment in network $i, \beta_{i}$ as productivity and $\psi(\cdot)$ as the (unobservable) capital cost.

${ }^{5}$ Contracting is under asymmetric information with the timing of this model. It is always debatable whether the regulated firm has all relevant information about its own productivity at the contracting stage. However, it is probably realistic to assume that firms can shut down their production at any point if it becomes unprofitable. With an interim participation constraint, the analysis is similar to the one presented here.
} 
productivity network and $\left(\widetilde{q}_{j}, \widetilde{t}_{j}\right)$ to the low productivity network. Regulation is transparent: The set of regulatory contracts as well as the productivity reports of the NSOs are common knowledge. Transparency simplifies the analysis and allows me to emphasize the welfare effects associated with different network structures, thus eliminating effects stemming from ad hoc restrictions on the set of enforceable contracts. Moreover, the transparency assumption is realistic in this setting. The European Commission (2007), for example, views transparency essential for a properly working market. I do not study the welfare effects of transparency here, but see Combes et al. (1997) who show that transparent regulation Pareto dominates "opaque" regulation in a Cournot model of regulated trade since the cost efficient firm has a larger market share under transparency (it is still open whether this result extends to the case of strategic complementarities).

Using $m_{i}=q_{i} / \beta_{i}$ and $t_{i}=u_{i}+\psi\left(m_{i}\right)$, I can write expected national welfare in country $i=1,2$ entirely in terms of quality $\mathbf{Q}=\left(\mathbf{q}_{1}, \mathbf{q}_{2}\right)$ and operator rent $\mathbf{u}_{i}=\left(\bar{u}_{i}, \widehat{u}_{i}, \widetilde{u}_{i}, \underline{u}_{i}\right)$ :

$$
\begin{aligned}
& W_{i}\left(\mathbf{Q}, \mathbf{u}_{i}\right)=v^{2}\left[P\left(\bar{q}_{1}, \bar{q}_{2}\right) \triangle S_{i}-(1+\lambda) \psi\left(\bar{q}_{i} / \bar{\beta}\right)-\lambda \bar{u}_{i}\right] \\
& \quad+v(1-v)\left[\left(P\left(\widehat{q}_{1}, \widetilde{q}_{2}\right)+P\left(\widetilde{q}_{1}, \widehat{q}_{2}\right)\right) \triangle S_{i}-(1+\lambda)\left(\psi\left(\widehat{q}_{i} / \bar{\beta}\right)+\psi\left(\widetilde{q}_{i} / \underline{\beta}\right)\right)-\lambda\left(\widehat{u}_{i}+\widetilde{u}_{i}\right)\right] \\
& \quad+(1-v)^{2}\left[P\left(\underline{q}_{1}, \underline{q}_{2}\right) \triangle S_{i}-(1+\lambda) \psi\left(\underline{q}_{i} / \underline{\beta}\right)-\lambda \underline{u}_{i}\right] .
\end{aligned}
$$

\section{Equilibrium policies}

To highlight the importance of network structure, I evaluate expected welfare and the optimal policies under the various structures against the first-best, complete information solution. Under complete information about productivity and for any regulatory policy, it is optimal to set operator rent as low as possible since transfers bear with them a social cost. System operation is voluntary. With an outside option equal to zero, the minimal transfers are at the point at which system operation is just profitable: $\mathbf{u}_{1}=\mathbf{u}_{2}=\mathbf{0}$. To ensure the existence of an optimum, I employ a boundary condition:

For $i \neq j=1,2, \exists k>0$ such that $P_{i}^{\prime}(q)\left(\triangle S_{1}+\triangle S_{2}\right)<(1+\lambda) \psi^{\prime}\left(q_{i} / \bar{\beta}\right) / \bar{\beta} \forall q_{i}>k, \forall q_{j} \geq 0$

throughout the analysis. This boundary condition is satisfied if the marginal maintenance cost goes to infinity or if marginal network reliability goes to zero as maintenance spending goes to infinity. Straightforward maximization of aggregate welfare $W_{1}(\mathbf{Q}, \mathbf{0})+W_{2}(\mathbf{Q}, \mathbf{0})$ over $\mathbf{Q}$ yields:

Lemma 1 The first-best policy is unique and symmetric, $\mathbf{q}_{1}^{f b}=\mathbf{q}_{2}^{f b}=\mathbf{q}^{f b}=\left(\bar{q}^{f b}, \widehat{q}^{f b}, \widetilde{q}^{f b}, \underline{q}^{f b}\right)$, and characterized by:

$$
\begin{aligned}
& \left.P_{1}^{\prime}\left(\bar{q}^{f b}, \bar{q}^{f b}\right)\left(\triangle S_{1}+\triangle S_{2}\right)=(1+\lambda) \psi^{\prime}\left(\bar{q}^{f b} / \bar{\beta}\right)\right) / \bar{\beta} \\
& \left.P_{1}^{\prime}\left(\widehat{q}^{f b}, \widetilde{q}^{f b}\right)\left(\triangle S_{1}+\triangle S_{2}\right)=(1+\lambda) \psi^{\prime}\left(\widehat{q}^{f b} / \bar{\beta}\right)\right) / \bar{\beta} \\
& \left.P_{1}^{\prime}\left(\widetilde{q}^{f b}, \widehat{q}^{f b}\right)\left(\triangle S_{1}+\triangle S_{2}\right)=(1+\lambda) \psi^{\prime}\left(\widetilde{q}^{f b} / \underline{\beta}\right)\right) / \underline{\beta} \\
& P_{1}^{\prime}\left(\underline{q}^{f b}, \underline{q}^{f b}\right)\left(\triangle S_{1}+\triangle S_{2}\right)=(1+\lambda)\left(\psi^{\prime}\left(\underline{q}^{f b} / \underline{\beta}\right)\right) / \underline{\beta} .
\end{aligned}
$$


Under quality complementarity, $\bar{q}^{f b}>\widehat{q}^{f b}$ and $\widetilde{q}^{f b}>\underline{q}^{f b}$, whereas $\widehat{q}^{f b}>\bar{q}^{f b}$ and $\widetilde{q}^{f b}>\underline{q}^{f b}$ under quality substitutability.

The proof is in the Appendix.

The first-best policy arises at the point at which the marginal benefit of network reliability equals the marginal social maintenance cost. Network reliability is a public good: The value of network reliability depends on the aggregate gains from trade. Therefore, the optimal policy is symmetric, although the gains from energy market integration may be asymmetrically distributed across countries $\left(\triangle S_{1} \neq \triangle S_{2}\right)$. The optimal distribution of maintenance spending across the network occurs at the point at which the marginal rate of substitution equals the marginal rate of technical substitution. In a network with asymmetric productivity $\left(\beta_{1}=\bar{\beta}>\underline{\beta}=\beta_{2}\right)$ :

$$
\frac{\bar{\beta} P_{1}^{\prime}\left(\widehat{q}^{f b}, \widetilde{q}^{f b}\right)}{\underline{\beta}_{2}^{\prime}\left(\widehat{q}^{f b}, \widetilde{q}^{f b}\right)}=\frac{\psi^{\prime}\left(\widehat{q}^{f b} / \bar{\beta}\right)}{\psi^{\prime}\left(\widetilde{q}^{f b} / \underline{\beta}\right)},
$$

which is independent of the aggregate gains from trade.

Quality varies less with productivity across the networks when network qualities are complements rather than substitutes. Under complementarity a productivity increase leads to higher quality in all parts of the network. Under substitutability, higher quality in one part of the network leads to lower quality in the other.

From an inspection of the conditions for optimal network quality, one might be tempted to conclude that higher gains from trade would always yield more network maintenance. This is not necessarily true. Under quality substitutability, more maintenance in one part of the network has the effect of depressing the marginal benefit of maintenance in the other. In principle, this substitution effect could dominate the direct "income" effect, rendering network quality an inferior good. In this paper I restrict attention to the case where network quality is a normal good, in the sense that an increase in the aggregate gains from trade leads to higher maintenance spending in all parts of the network under first-best regulation. A sufficient condition on network reliability is (stated here without proof):

$$
-P_{i j}^{\prime \prime} \leq\left|P_{j j}^{\prime \prime}\right| P_{i}^{\prime} / P_{j}^{\prime} \text { for all } q \geq 0, i \neq j=1,2
$$

If the degree of substitutability between $q_{i}$ and $q_{j}$ is sufficiently weak, the direct effect dominates the substitution effect. Condition (NG) is not particularly restrictive: It is satisfied under quality complementarity $\left(P_{i j}^{\prime \prime}>0\right)$ and even under perfect substitutability $\left(P(q)=p\left(q_{1}+q_{2}\right)\right)$.

Under complete information it does not matter whether there is a common system operator (CSO) or two national system operators (NSOs). In this model, a CSO spending $m_{1}$ and $m_{2}$ on maintenance in the two parts of the networks incurs the same maintenance cost $\psi\left(m_{1}\right)+\psi\left(m_{2}\right)$ as two NSOs spending $m_{1}$ and $m_{2}$ in their respective networks. Maintenance economies of scale would favour the creation of a single CSO under complete information, whereas two NSOs would be better under diseconomies of scale. The present paper emphasizes the effects of political 
constraints and incentives on optimal network structure. Therefore, I have not signed cost advantages in any direction.

\subsection{Separation}

Under Separation, a national regulatory agency (NRA) in each country has the responsibility for regulating the performance of a national system operator (NSO). I restrict attention to dominant strategy implementable direct (DSID) contracts; no NSO can strictly benefit from misrepresenting its productivity nor shutting down no matter what the other NSO reports. Under dominant strategy implementation regulatory policies are robust to collusive coordination among the NSOs and to any misconceptions each system operator might have about the actions of the other. Owing to transparency, a multi-principal Revelation Principle applies to this analysis: Every equilibrium of a regulation game with a more general message space, can equivalently be represented as the equilibrium of a game where both regulators have committed to offering direct DSID mechanisms; see the Appendix. ${ }^{6}$

By transparency, NRA $i$ can condition the regulatory policy on the productivity reports of both NSOs. Notwithstanding stochastic independence of information, NRA $i$ still benefits from conditioning regulation on both reports because network reliability depends on quality in all parts of the network. Any contract accepted by the NSO in country $i=1,2$ must first satisfy the participation constraint

$$
\mathbf{u}_{i} \geq 0
$$

whereby it is required that system operation always be profitable no matter the system operator's own productivity and its subjective belief about the productivity report of the other. The first requirement of incentive compatibility is that the high productivity NSO in country $i=1,2$ cannot benefit from understating productivity independently of its beliefs about the productivity report of the NSO in country $j$ :

$$
\begin{array}{ll}
\bar{u}_{i} \geq \widetilde{u}_{i}+\psi\left(\widetilde{q}_{i} / \underline{\beta}\right)-\psi\left(\widetilde{q}_{i} / \bar{\beta}\right)=\widetilde{u}_{i}+\Phi\left(\widetilde{q}_{i}\right) \\
\widehat{u}_{i} \geq \underline{u}_{i}+\psi\left(\underline{q}_{i} / \underline{\beta}\right)-\psi\left(\underline{q}_{i} / \bar{\beta}\right)=\underline{u}_{i}+\Phi\left(\underline{q}_{i}\right)
\end{array}
$$

The high productivity NSO can always secure itself a positive rent by understating productivity, as it must spend comparatively little, $q_{i} / \bar{\beta}$ versus $q_{i} / \underline{\beta}$, on maintenance to reach a given level $q_{i}$ of quality. The value of this advantage is precisely the cost differential $\Phi\left(q_{i}\right)$ above. To preserve incentive compatibility, NRA $i$ must compensate NSO $i$ this informational rent. The informational rent is increasing in the regulated quality of the low productivity network owing to decreasing returns to maintenance spending $\left(\psi^{\prime \prime}>0, \psi^{\prime \prime \prime} \geq 0\right)$ : $\Phi$ is increasing and convex $\left(\Phi^{\prime}(0)=0, \Phi^{\prime \prime}>0\right)$. The second requirement of incentive compatibility is that the low

\footnotetext{
${ }^{6}$ If the regulatory contracts were not public (transparent), the restriction to direct and incentive compatible contracts might come at a loss in generality (Attar et al., 2010). Also, the set of equilibria could potentially be very large (Yamashita, 2010).
} 
productivity NSO is always better off reporting the truth than overstating productivity to $\bar{\beta}$ :

$$
\widetilde{u}_{i} \geq \bar{u}_{i}-\Phi\left(\bar{q}_{i}\right), \underline{u}_{i} \geq \widehat{u}_{i}-\Phi\left(\widehat{q}_{i}\right) .
$$

The dishonest low productivity NSO is worse off than the honest high productivity NSO due to the former type's competitive disadvantage of delivering quality.

The regulator in country $i$ chooses the policy $\left(\mathbf{q}_{i}, \mathbf{u}_{i}\right)$ to maximize expected national welfare $W_{i}\left(\mathbf{Q}, \mathbf{u}_{i}\right)$ subject to the above participation and incentive constraints, taking the policy $\left(\mathbf{q}_{j}, \mathbf{u}_{j}\right)$ in the other country as given. The contracts $\left(\mathbf{q}_{1}^{S}, \mathbf{u}_{1}^{S}\right)$ and $\left(\mathbf{q}_{2}^{S}, \mathbf{u}_{2}^{S}\right)$ constitute a Nash Equilibrium under Separation if each contract is DSID and no regulator can raise national welfare by a unilateral deviation to another DSID contract. By standard arguments, see e.g. Chapter 1 in Laffont and Tirole (1993), the DSID constraints can be replaced by a binding participation constraint for the low type $\left(\widetilde{u}_{i}=\underline{u}_{i}=0\right)$, binding downward incentive constraints $\left(\overline{I C}^{S}\right)$, and the monotonicity constraint

$$
\bar{q}_{i} \geq \widetilde{q}_{i}, \widehat{q}_{i} \geq \underline{q}_{i}
$$

The regulator wants to minimize operator rent due to the shadow price of public funds. It is the high productivity NSO that must be compensated for revealing its type, because this NSO has the most to gain from lying. It is unnecessary to leave any rent to the low productivity NSO because it cannot benefit from lying about its type. Substituting $\mathbf{u}_{i}=\left(\Phi\left(\widetilde{q}_{i}\right), \Phi\left(\underline{q}_{i}\right), 0,0\right)$ into (1), I can write national welfare under Separation entirely in terms of quality $\mathbf{Q}$ :

$$
\begin{aligned}
& W_{i}^{S}(\mathbf{Q})=v^{2}\left[P\left(\bar{q}_{1}, \bar{q}_{2}\right) \triangle S_{i}-(1+\lambda) \psi\left(\bar{q}_{i} / \bar{\beta}\right)\right] \\
& +v(1-v)\left[\left(P\left(\widehat{q}_{1}, \widetilde{q}_{2}\right)+P\left(\widetilde{q}_{1}, \widehat{q}_{2}\right)\right) \triangle S_{i}-(1+\lambda)\left(\psi\left(\widehat{q}_{i} / \bar{\beta}\right)+\psi\left(\widetilde{q}_{i} / \beta\right)+\frac{v}{1-v} \frac{\lambda}{1+\lambda} \Phi\left(\widetilde{q}_{i}\right)\right)\right] \\
& +(1-v)^{2}\left[P\left(\underline{q}_{1}, \underline{q}_{2}\right) \triangle S_{i}-(1+\lambda)\left(\psi\left(\underline{q}_{i} / \underline{\beta}\right)+\frac{v}{1-v} \frac{\lambda}{1+\lambda} \Phi\left(\underline{q}_{i}\right)\right)\right] .
\end{aligned}
$$

Maximization of $W_{i}^{S}(\mathbf{Q})$ subject to $\bar{q}_{i} \geq \widetilde{q}_{i}$ and $\widehat{q}_{i} \geq \underline{q}_{i}$ yields:

Lemma 2 There exists a unique equilibrium $\mathbf{Q}^{S}=\left(\mathbf{q}_{1}^{S}, \mathbf{q}_{2}^{S}\right)$ under Separation (for generic parameter values), where $\mathbf{q}_{1}^{S}=\left(\bar{q}_{1}^{S}, \widehat{q}_{1}^{S}, \widetilde{q}_{1}^{S}, \underline{q}_{1}^{S}\right)$ is characterized by

$$
\begin{aligned}
& P_{1}^{\prime}\left(\bar{q}_{1}^{S}, \bar{q}_{2}^{S}\right) \triangle S_{1}=(1+\lambda) \psi^{\prime}\left(\bar{q}_{1}^{S} / \bar{\beta}\right) / \bar{\beta} \\
& P_{1}^{\prime}\left(\widehat{q}_{1}^{S}, \widetilde{q}_{2}^{S}\right) \triangle S_{1}=(1+\lambda) \psi^{\prime}\left(\widehat{q}_{1}^{S} / \bar{\beta}\right) / \bar{\beta} \\
& P_{1}^{\prime}\left(\widetilde{q}_{1}^{S}, \widehat{q}_{2}^{S}\right) \triangle S_{1}=(1+\lambda)\left(\psi^{\prime}\left(\widetilde{q}_{1}^{S} / \underline{\beta}\right) / \underline{\beta}+\frac{v}{1-v} \frac{\lambda}{1+\lambda} \Phi^{\prime}\left(\widetilde{q}_{1}^{S}\right)\right) \\
& P_{1}^{\prime}\left(\underline{q}_{1}^{S}, \underline{q}_{2}^{S}\right) \triangle S_{1}=(1+\lambda)\left(\psi^{\prime}\left(\underline{q}_{1}^{S} / \underline{\beta}\right) / \underline{\beta}+\frac{v}{1-v} \frac{\lambda}{1+\lambda} \Phi^{\prime}\left(\underline{q}_{1}^{S}\right)\right),
\end{aligned}
$$

and analogously for $\mathbf{q}_{2}^{S}=\left(\bar{q}_{2}^{S}, \widehat{q}_{2}^{S}, \widetilde{q}_{2}^{S}, \underline{q}_{2}^{S}\right)$. Network reliability is too low relative to the first-best policy if network quality is a normal good (condition ( $N G$ ) holds), but the country with the largest gains from energy market integration spends too much on maintenance relative to the other. 
The proof is in the Appendix.

The equilibrium policies $\mathbf{q}_{1}^{S}$ and $\mathbf{q}_{2}^{S}$ deviate from the first-best solution $\mathbf{q}^{f b}$ in three respects, two of which have to do with the non-cooperative manner in which the regulatory policies are set under Separation. Network reliability is a public good. By failing to take into account the positive externality of increased network reliability, the national regulatory agency spends too little on maintenance: The full marginal effect is $P_{i}^{\prime}(q)\left(\triangle S_{1}+\triangle S_{2}\right)$, whereas NRA $i$ only cares about $P_{i}^{\prime}(q) \triangle S_{i}$.

Second, the regulatory policies suffer from productive inefficiencies. The distribution of maintenance spending is given by

$$
\frac{\bar{\beta} P_{1}^{\prime}\left(\widehat{q}_{1}^{S}, \widetilde{q}_{2}^{S}\right) \triangle S_{1}}{\underline{\beta} P_{2}^{\prime}\left(\widehat{q}_{1}^{S}, \widetilde{q}_{2}^{S}\right) \triangle S_{2}}=\frac{\psi^{\prime}\left(\widehat{q}_{1}^{S} / \bar{\beta}\right)}{\psi^{\prime}\left(\widetilde{q}_{2}^{S} / \underline{\beta}\right)+\frac{v}{1-v} \frac{\lambda}{1+\lambda} \underline{\beta}^{\prime}\left(\widetilde{q}_{2}^{S}\right)}
$$

when the two networks are asymmetric $\left(\beta_{1}=\bar{\beta}>\beta_{2}=\underline{\beta}\right)$. With asymmetric gains from trade (say, $\triangle S_{1}>\triangle S_{2}$ ), the high-productivity network tends to spend comparatively much on maintenance because the perceived relative marginal benefit of network reliability is too high.

Third, maintenance under-spending is exacerbated by the presence of asymmetric information. Suppose the regulator wants to increase maintenance spending in the low productivity NSO, e.g. raise $\widetilde{q}_{i}$ marginally. To preserve the profitability of system operation the regulator must increase the transfers to the low productivity NSOs in proportion to the extra maintenance cost. Since transfers are costly, the marginal social maintenance cost is $(1+\lambda) \psi^{\prime}\left(\widetilde{q}_{i} / \underline{\beta}\right) / \underline{\beta}$. Under asymmetric information, all types of NSOs benefit from more high-powered incentives because the regulator cannot ex ante target transfers to low productivity NSOs. To preserve incentive compatibility, the regulator must compensate also the high productivity NSO by awarding it additional transfers. This spill-over effect, the informational rent, leads to a virtual marginal maintenance cost

$$
(1+\lambda)\left(\psi^{\prime}\left(\widetilde{q}_{i} / \underline{\beta}\right) / \underline{\beta}+\frac{v}{1-v} \frac{\lambda}{1+\lambda} \Phi^{\prime}\left(\widetilde{q}_{i}\right)\right)
$$

in excess of the marginal social maintenance cost. Under asymmetric information, optimal maintenance spending is found at the point at which the marginal benefit of network reliability equals the virtual marginal maintenance cost. The higher is the shadow price $\lambda$ of public funds, the higher is the probability $v$ that the NSO is of a high productivity and the stronger is the cost advantage of the high productivity NSO (the higher is $\Phi^{\prime}$ ), the higher is the virtual marginal maintenance cost and the lower is equilibrium maintenance spending.

Brainard and Martimort (1996) analyse a multi-principal, multi-agent game with some similarities to the game above. In a game of strategic trade policy under asymmetric information, each government offers the home firm a production subsidy to compete with an equally subsidized foreign firm in a third country market. Under the assumption that each government maximizes the domestic firm's rent (less the social cost of the subsidy), production subsidies are excessive because product market competition locks the two governments in a prisoner's dilemma. Asymmetric information serves to reduce policy distortions by increasing the virtual marginal cost of 
production subsidies. In the present context, the fundamental coordination problem stems from free riding on a public good (network reliability), not competition. The focus is on aggregate welfare (including consumer's surplus) and not on firm rent. Consequently, production subsidies are too small, and asymmetric information only adds to the problem. Brainard and Martimort (1996) restrict attention to the symmetric case and therefore do not address productive inefficiencies stemming from asymmetric gains from trade. ${ }^{7}$ Finally, a multiplicity of equilibria complicates their welfare analysis, whereas the present model yields a unique equilibrium.

\subsection{Common regulation}

Asymmetric gains from energy market integration $\left(\triangle S_{1} \neq \triangle S_{2}\right)$ imply that the two national regulatory agencies (NRAs) choose different policies under Separation $\left(\mathbf{q}_{1}^{S} \neq \mathbf{q}_{2}^{S}\right)$. Under Common regulation, the regulatory responsibility is collected in the hands of a common regulatory agency (CRA). Yet, conflict over the optimal regulatory policy is not likely to vanish with the introduction of a common regulatory agency if the asymmetric gains from trade remain also under Common regulation. The desirability of Common regulation then depends on how the preferences of the different countries are aligned within the CRA. The simplest way of introducing political conflict is to assume that the CRA maximizes a weighted average of national welfare

$$
\mu_{1} W_{1}\left(\mathbf{Q}, \mathbf{u}_{1}\right)+\mu_{2} W_{2}\left(\mathbf{Q}, \mathbf{u}_{2}\right),\left(\mu_{1}, \mu_{2}\right) \geq 0, \mu_{1}+\mu_{1}=1
$$

A relevant special case of this representation is majority voting whereby whoever holds the majority in the board of directors, exercises dictatorial powers over the design the regulation ( $\mu_{i}=1$ if country $i$ is in majority).

This seemingly innocuous representation carries the seeds of severe political exploitation. The common regulatory agency has the powers to tax the inhabitants in both countries to finance system operation. Under simple majority rule, the CRA tailors its policy to maximize welfare $W_{i}\left(\mathbf{Q}, \mathbf{u}_{i}\right)$ in the majority country $i$, independently of the consequences for welfare in the minority country $j$. With a perceived shadow price of public funds equal to zero in country $j$, the CRA would profit from collecting excessive transfers from country $j$ to finance NSO $i$ 's system operation. A proportionality rule would curb such transfer exploitation. Under proportionality transfers should stand in relation to the cost of system operation in the country where they are collected. Proportionality is not enough, however. Under simple majority rule, the majority still has an incentive to overinvest in the minority network and finance it by means of local transfers. Increased network reliability benefits the majority, but the perceived shadow price on transfers is minimal $\left(\partial W_{i} / \partial \mathbf{q}_{j}>\mathbf{0}\right)$. This problem of excessive network investment is relieved by the imposition of a non-discrimination rule whereby maintenance spending is required to be a function only of the productivity of the networks and not allowed to depend on the country in which the network is located. In the present setting, non-discrimination implies symmetric

\footnotetext{
${ }^{7}$ Analyzing asymmetries is difficult in their setting because the model features a continuum of types. Characterizing asymmetric equilibria then amounts to finding the solution to a pair of asymmetric differential equations. Introducing asymmetries is straightforward with a discrete type space.
} 
regulatory policies: $\mathbf{q}_{1}=\mathbf{q}_{2}=\mathbf{q}=(\bar{q}, \widehat{q}, \widetilde{q}, \underline{q})$ and $\mathbf{u}_{1}=\mathbf{u}_{2}=\mathbf{u}=(\bar{u}, \widehat{u}, \widetilde{u}, \underline{u})$. Conversely, symmetry implies non-discrimination and proportionality. ${ }^{8}$

Under proportionality and non-discrimination, the CRA sets $\mathbf{q}$ and $\mathbf{u}$ to maximize $\mu_{1} W_{1}(\mathbf{q}, \mathbf{q}, \mathbf{u})+$ $\mu_{2} W_{2}(\mathbf{q}, \mathbf{q}, \mathbf{u})$ subject to the participation constraint

$$
\mathbf{u} \geq 0
$$

and incentive compatibility constraints

$$
\begin{aligned}
& \bar{u} \geq \widetilde{u}+\Phi(\widetilde{q}), \widehat{u} \geq \underline{u}+\Phi(\underline{q}), \\
& \widetilde{u} \geq \bar{u}-\Phi(\bar{q}), \underline{u} \geq \widehat{u}-\Phi(\widehat{q}) .
\end{aligned}
$$

As under Separation, the relevant constraints are downward incentive compatibility $\left(\overline{I C}^{C r}\right)$, low type participation $(\widetilde{u}=\underline{u}=0)$ and monotonicity

$$
\bar{q} \geq \widetilde{q}, \widehat{q} \geq \underline{q}
$$

Operator rent is minimized by extracting all surplus from the low type while paying the high type precisely the informational rent. Substituting $\mathbf{u}=(\Phi(\widetilde{q}), \Phi(\underline{q}), 0,0)$ into the symmetric weighted welfare function I obtain the common regulatory agency's policy function

$$
\begin{aligned}
\Gamma^{C r}(\mathbf{q}) & =v^{2}\left[P(\bar{q}, \bar{q})\left(\mu_{1} \triangle S_{1}+\mu_{2} \triangle S_{2}\right)-(1+\lambda) \psi(\bar{q} / \bar{\beta})\right] \\
& +v(1-v)\left[2 P(\widehat{q}, \widetilde{q})\left(\mu_{1} \triangle S_{1}+\mu_{2} \triangle S_{2}\right)-(1+\lambda)\left(\psi(\widehat{q} / \bar{\beta})+\psi(\widetilde{q} / \underline{\beta})+\frac{v}{1-v} \frac{\lambda}{1+\lambda} \Phi(\widetilde{q})\right)\right] \\
& +(1-v)^{2}\left[P(\underline{q}, \underline{q})\left(\mu_{1} \triangle S_{1}+\mu_{2} \triangle S_{2}\right)-(1+\lambda)\left(\psi(\underline{q} / \underline{\beta})+\frac{v}{1-v} \frac{\lambda}{1+\lambda} \Phi(\underline{q})\right)\right] .
\end{aligned}
$$

Maximizing $\Gamma^{C r}(\mathbf{q})$ over $\mathbf{q}$ and subject to $\bar{q} \geq \widetilde{q}$ and $\widehat{q} \geq \underline{q}$ yields:

Lemma 3 Under Common regulation, the unique symmetric optimal policy $\mathbf{q}^{C r}=\left(\bar{q}^{C r}, \widehat{q}^{C r}, \widetilde{q}^{C r}, \underline{q}^{C r}\right)$ is characterized by

$$
\begin{aligned}
& 2 P_{1}^{\prime}\left(\bar{q}^{C r}, \bar{q}^{C r}\right)\left(\mu_{1} \triangle S_{1}+\mu_{2} \triangle S_{2}\right)=(1+\lambda) \psi^{\prime}\left(\bar{q}^{C r} / \bar{\beta}\right) / \bar{\beta} \\
& 2 P_{1}^{\prime}\left(\widehat{q}^{C r}, \widetilde{q}^{C r}\right)\left(\mu_{1} \triangle S_{1}+\mu_{2} \triangle S_{2}\right)=(1+\lambda) \psi^{\prime}\left(\widehat{q}^{C r} / \bar{\beta}\right) / \bar{\beta} \\
& 2 P_{1}^{\prime}\left(\widetilde{q}^{C r}, \widehat{q}^{C r}\right)\left(\mu_{1} \triangle S_{1}+\mu_{2} \triangle S_{2}\right)=(1+\lambda)\left(\psi^{\prime}\left(\widetilde{q}^{C r} / \underline{\beta}\right) / \underline{\beta}+\frac{v}{1-v} \frac{\lambda}{1+\lambda} \Phi^{\prime}\left(\widetilde{q}^{C r}\right)\right) \\
& 2 P_{1}^{\prime}\left(\underline{q}^{C r}, \underline{q}^{C r}\right)\left(\mu_{1} \triangle S_{1}+\mu_{2} \triangle S_{2}\right)=(1+\lambda)\left(\psi^{\prime}\left(\underline{q}^{C r} / \underline{\beta}\right) / \underline{\beta}+\frac{v}{1-v} \frac{\lambda}{1+\lambda} \Phi^{\prime}\left(\underline{q}^{C r}\right)\right) .
\end{aligned}
$$

If network quality is a normal good, then quality increases the more weight is placed on the national welfare of country with the largest gains from trade (If condition (NG) holds and $\triangle S_{i}>$

\footnotetext{
${ }^{8}$ Observe that the NSOs are treated symmetrically ex ante because they are offered the same menu of contracts to choose from, but are treated asymmetrically ex post if they choose different contracts.
} 
$\triangle S_{j}$, then $\left.\partial \mathbf{q}^{C r} / \partial \mu_{i}>0\right) .^{9}$

The proof is in the Appendix.

Concentrating regulatory responsibility in the hands of a single regulatory agency gets rid of the productive inefficiency because maintenance spending is now optimally distributed throughout the network. With asymmetric network productivity $\left(\beta_{1}=\bar{\beta}>\beta_{2}=\underline{\beta}\right)$ :

$$
\frac{\bar{\beta}}{\underline{\beta}} \frac{P_{1}^{\prime}\left(\widehat{q}^{C r}, \widetilde{q}^{C r}\right)}{P_{2}^{\prime}\left(\widehat{q}^{C r}, \widetilde{q}^{C r}\right)}=\frac{\psi^{\prime}\left(\widehat{q}^{C r} / \bar{\beta}\right)}{\psi^{\prime}\left(\widetilde{q}^{C r} / \underline{\beta}\right)+\frac{v}{1-v} \frac{\lambda}{1+\lambda} \underline{\beta} \Phi^{\prime}\left(\widetilde{q}^{C r}\right)},
$$

which is independent of the distribution $\left(\mu_{1}, \mu_{2}\right)$ of political power. Establishing a common regulatory agency has no bearing on the agency problem. The incentive distortion persists, and the marginal rate of substitution equals the virtual marginal technical rate of substitution.

There could be over- or under-spending under Common regulation depending on the distribution of political power. If the gains from trade are asymmetrically distributed across the countries $\left(\triangle S_{i}>\triangle S_{j}\right)$, the perceived marginal benefit of network reliability under Common regulation is higher the more weight is placed on the country with the most to gain from integration and therefore maintenance spending is higher. Under simple majority rule $\left(\mu_{i}=1\right)$ there will be excessive maintenance spending even compared to the first-best $\left(\mathbf{q}^{C r}>\mathbf{q}^{f b}\right)$ if the social cost of transfers $(\lambda v)$ is low.

\subsection{Integration}

Under the framework of Integration, system operation is concentrated in the hands of a common system operator (CSO), regulated by a common regulatory agency (CRA). To emphasize the effect of network structure, I assume sub-cost observability: The regulator observes and can contract on $q_{1}$ and $q_{2}$ separately even when there is a single system operator. If the regulator could observe and contract upon only a composite function of quality $q$, say network reliability $P(q)$, Integration would be less appealing because of a narrower span of enforceable contracts. I discuss the implications of sub-cost observability below; see also Laffont and Tirole (1993).

The regulatory problem under Integration is one of multi-dimensional asymmetric information. Any feasible contract must satisfy the participation constraint:

$$
u(\beta)=\sum_{i=1,2}\left[t_{i}(\beta)-\psi\left(q_{i}(\beta) / \beta_{i}\right)\right] \geq 0 \forall \beta \in\{\underline{\beta}, \bar{\beta}\}^{2}
$$

\footnotetext{
${ }^{9}$ The restriction to dominant strategy implementable direct (DSID) contracts is without loss of generality here. Optimality of direct contracts follows from the Revelation Principle. Under Bayesiean implementation, the downward-binding incentive constraint is $v \bar{u}+(1-v) \widehat{u}=v(\widetilde{u}+\Phi(\widetilde{q}))+(1-v)(\underline{u}+\Phi(q))$, the low type's participation constraint is $v \widetilde{u}+(1-v) \underline{u}=0$, and the monotonicity constraint is $v \Phi(\bar{q})+(1-v) \Phi(\widehat{q}) \geq v \Phi(\widetilde{q})+(1-v) \Phi(q)$. Substituting expected operator $\operatorname{rent} v \Phi(\widetilde{q})+(1-v) \Phi(q)$ into the policy function and maximizing over q yields (8). The monotonicity constraint is satisfied by this solution because $\bar{q}^{C r}>\widetilde{q}^{C r}$ and $\widehat{q}^{C r}>\underline{q}^{C r}$. Hence, Bayesian and dominant strategy implementation yield exactly the same optimal policy; see Mookherjee and Reichelstein (1992) for more on this topic.
} 
and the incentive compatibility constraint

$$
u(\beta) \geq \sum_{i=1,2}\left[t_{i}(b)-\psi\left(q_{i}(b) / \beta_{i}\right)\right] \forall(b, \beta) \in\{\underline{\beta}, \bar{\beta}\}^{4} .
$$

The CSO possesses an informational advantage over the two national system operators NSOs as the CSO (by assumption) holds private information about the productivity $\beta=\left(\beta_{1}, \beta_{2}\right)$ of the entire grid. Unlike the two NSOs, the CSO is able to coordinate the performance of the various parts of the grid to maximize informational rent (recall, the regulatory policies are in dominating strategies under Common regulation): The CSO has more agency power than the two NSOs. The advantage of having fewer system operators is cross-subsidization: It is only necessary to meet the aggregate profitability and incentive constraints of the CSO, and not one for each individual NSO. These costs and benefits will be more apparent later. As under Common regulation, political conflict may yield incentives for transfer exploitation across countries. I therefore assume that contracts are required to be symmetric even under Integration.

Even here the main concern is the incentive of the CSO for understating the productivity of the network. Therefore, the feasibility constraints $\left(P C^{I}\right)$ and $\left(I C^{I}\right)$ can be replaced by the lowest type's participation constraint $\underline{u}=\widetilde{u}=0$, the downward-binding incentive compatibility constraints

$$
\begin{aligned}
2 \bar{u} & =\max \{\widehat{u}+\widetilde{u}+\Phi(\widetilde{q}) ; 2 \underline{u}+2 \Phi(\underline{q})\} \\
\widehat{u}+\widetilde{u} & =2 \underline{u}+\Phi(\underline{q})
\end{aligned},
$$

and the monotonicity constraint:

$$
\min \{\bar{q} ; \widehat{q}\} \geq \max \{\widetilde{q} ; \underline{q}\} .
$$

Substituting the binding constraints into the policy function $\mu_{1} W_{1}(\mathbf{q}, \mathbf{q}, \mathbf{u})+\mu_{2} W_{2}(\mathbf{q}, \mathbf{q}, \mathbf{u})$, the CRA's problem reduces to maximizing

$$
\begin{aligned}
\Gamma^{I}(\mathbf{q}, \bar{u}) & =v^{2}\left[P(\bar{q}, \bar{q})\left(\mu_{1} \triangle S_{1}+\mu_{2} \triangle S_{2}\right)-(1+\lambda) \psi(\bar{q} / \bar{\beta})\right]-\lambda v^{2} \bar{u} \\
& +v(1-v)\left[2 P(\widehat{q}, \widetilde{q})\left(\mu_{1} \triangle S_{1}+\mu_{2} \triangle S_{2}\right)-(1+\lambda)(\psi(\widehat{q} / \bar{\beta})+\psi(\widetilde{q} / \underline{\beta}))\right] \\
& +(1-v)^{2}\left[P(\underline{q}, \underline{q})\left(\mu_{1} \triangle S_{1}+\mu_{2} \triangle S_{2}\right)-(1+\lambda)\left(\psi(\underline{q} / \underline{\beta})+\frac{\lambda}{1+\lambda} \frac{v}{1-v} \Phi(\underline{q})\right)\right]
\end{aligned}
$$

over $\mathbf{q}$ and $\bar{u}$, subject to $2 \bar{u} \geq \Phi(\underline{q})+\max \{\Phi(\widetilde{q}) ; \Phi(\underline{q})\}$ and monotonicity $(9)$ :

Lemma 4 The optimal symmetric policy $\mathbf{q}^{I}=\left(\bar{q}^{I}, \widehat{q}^{I}, \widetilde{q}^{I}, \underline{q}^{I}\right)$, under Integration is characterized 


$$
\begin{aligned}
2 P_{1}^{\prime}\left(\bar{q}^{I}, \bar{q}^{I}\right)\left(\mu_{1} \triangle S_{1}+\mu_{2} \triangle S_{2}\right) & =(1+\lambda) \psi^{\prime}\left(\bar{q}^{I} / \bar{\beta}\right) / \bar{\beta} \\
2 P_{1}^{\prime}\left(\widehat{q}^{I}, \widetilde{q}^{I}\right)\left(\mu_{1} \triangle S_{1}+\mu_{2} \triangle S_{2}\right) & =(1+\lambda) \psi^{\prime}\left(\widehat{q}^{I} / \bar{\beta}\right) / \bar{\beta} \\
2 P_{1}^{\prime}\left(\widetilde{q}^{I}, \widehat{q}^{I}\right)\left(\mu_{1} \triangle S_{1}+\mu_{2} \triangle S_{2}\right) & =(1+\lambda)\left(\psi^{\prime}\left(\widetilde{q}^{I} / \underline{\beta}\right) / \underline{\beta}+\frac{v}{1-v} \frac{\lambda}{1+\lambda} \frac{\widetilde{\xi}^{I}}{\lambda v^{2}} \Phi^{\prime}\left(\widetilde{q}^{I}\right)\right) \\
2 P_{1}^{\prime}\left(\underline{q}^{I}, \underline{q}^{I}\right)\left(\mu_{1} \triangle S_{1}+\mu_{2} \triangle S_{2}\right) & =(1+\lambda)\left(\psi^{\prime}\left(\underline{q}^{I} / \underline{\beta}\right) / \underline{\beta}+\frac{v}{1-v} \frac{\lambda}{1+\lambda}\left(1+\frac{\lambda v^{2}+2 \underline{\xi}^{I}}{2 \lambda v(1-v)}\right) \Phi^{\prime}\left(\underline{q}^{I}\right)\right) \\
\widetilde{\xi}^{I}+\underline{\xi}^{I} & =\lambda v^{2} / 2 \\
\widetilde{\xi}^{I}\left(2 \bar{u}^{I}-\Phi\left(\underline{q}^{I}\right)-\Phi\left(\widetilde{q}^{I}\right)\right) & =0 \\
\underline{\xi}^{I}\left(2 \bar{u}^{I}-2 \Phi\left(\underline{q}^{I}\right)\right) & =0,
\end{aligned}
$$

where $\widetilde{\xi}^{I} \geq 0$ and $\underline{\xi}^{I} \geq 0$ are the Kuhn-Tucker multipliers associated with $2 \bar{u}^{I} \geq \Phi\left(\underline{q}^{I}\right)+\Phi\left(\widetilde{q}^{I}\right)$ and $2 \bar{u}^{I} \geq 2 \Phi\left(\underline{q}^{I}\right)$. If network quality is a normal good (condition (NG) holds), then $P\left(\widehat{q}^{I}, \widetilde{q}^{I}\right)>$ $P\left(\widehat{q}^{C r}, \widetilde{q}^{C r}\right)$, but $P\left(\underline{q}^{I}, \underline{q}^{I}\right)<P\left(\underline{q}^{C r}, \underline{q}^{C r}\right)$.

The proof is in the Appendix.

Under Integration, coordination of maintenance spending yields productive efficiency, same as under Common regulation. However, productive efficiency depends on the ability of the NRA to contract on $q_{1}$ and $q_{2}$, separately. Suppose instead that the NRA can only contract on network reliability $p$. This contractual incompleteness implies that the NRA is forced to delegate the distribution of maintenance spending to the CSO. If network productivity differs across the network $\left(\beta_{1}=\bar{\beta}>\underline{\beta}=\beta_{2}\right)$, the CSO's cost-minimizing choice of maintenance spending is characterized by:

$$
\frac{\bar{\beta} P_{1}^{\prime}\left(\widehat{q}^{I}, \widetilde{q}^{I}\right)}{\underline{\beta} P_{2}^{\prime}\left(\widehat{q}^{I}, \widetilde{q}^{I}\right)}=\frac{\psi^{\prime}\left(\widehat{q}^{I} / \bar{\beta}\right)}{\psi^{\prime}\left(\widetilde{q}^{I} / \underline{\beta}\right)} \geq \frac{\psi^{\prime}\left(\widehat{q}^{I} / \bar{\beta}\right)}{\psi^{\prime}\left(\widetilde{q}^{I} / \underline{\beta}\right)+\underline{\beta} \frac{v}{1-v} \frac{\lambda}{1+\lambda} \frac{\widetilde{\xi}^{I}}{\lambda v^{2}} \Phi^{\prime}\left(\widetilde{q}^{I}\right)}, P\left(\widehat{q}^{I}, \widetilde{q}^{I}\right)=p .
$$

Under delegation, the CSO fails to internalize the social cost of operator rent and therefore spends too much on maintenance in the low productivity part of the network compared to the second-best. Productive inefficiency stemming from delegation would render Integration less appealing from a welfare point of view.

Differences arise between Common regulation and Integration even absent any delegation problems under Integration. Under Common regulation, two system operators independently strive to maximize their rent. Under Integration, a single system operator exercises agency power. The ability to jointly understate the performance of the common network (report $(\beta, \beta)$ when the true type is $(\bar{\beta}, \bar{\beta})$ ) jacks up the virtual marginal maintenance cost of the least productive network (of type $(\bar{\beta}, \bar{\beta})$ ) and reduces the virtual marginal maintenance cost of intermediate networks $\left(\beta_{i}=\bar{\beta}>\underline{\beta}=\beta_{j}\right)$ under Integration. ${ }^{10}$ Agency power thus yields more extreme

\footnotetext{
${ }^{10}$ The difference in virtual marginal maintenance cost between Integration and Common regulation equals
} 
incentives with network quality less distorted in the intermediate case and more distorted in the low productivity case under Integration than Common regulation.

\section{Comparison of network structures}

Common regulation versus Separation System operators spend too little on network maintenance under Separation by failing to internalize gains from energy integration abroad. Production inefficiencies stemming from uncoordinated maintenance expenditures exacerbate the distortions. The common regulatory agency (CRA) restores coordination and thus productive efficiency, but does not necessarily correct the distortions in aggregate maintenance spending appropriately. Whether Common regulation generates incentives for excessive or inferior maintenance spending depends on how the CRA balances the political influence $\left(\mu_{1}, \mu_{2}\right)$ of the two member states. Too much weight on the country that values energy integration the most $\left(\mu_{i}\right.$ is high when $\triangle S_{i}>\triangle S_{j}$ ) leads to over-spending owing to exaggerated perceived gains from trade. Under-spending occurs when the perceived gains from trade are underrated. Appropriate maintenance spending requires balanced political influence:

Proposition 1 Assume that network quality is a normal good. Common regulation then welfare dominates Separation if and only if political influence of the two countries is balanced. Separation strictly welfare dominates Common regulation and Integration if political influence is biased strongly in favour of a country with little to gain from market integration.

The proof is in the Appendix.

With an equal distribution of political influence across countries, no member state can exert enough influence over the regulatory policy to tilt it in one's own favour. With political balance, the regulatory policy maximizes total welfare. Under simple majority voting, political balance is strongly biased: The median voter holds dictatorial powers over regulatory policy. If it so happens that the median voter is located in a country with small gains from market integration, the problem of inferior maintenance spending is so serious that productive inefficiencies become of second order for network reliability. Maintaining multiple regulators then is better from a welfare perspective than creating a common regulatory agency.

What kind of political process could possibly lead to the creation of a common regulatory agency (CRA) whose policies would be to the detriment of individual member states? Obviously, if the policies of the common regulatory agency would be subject to unanimous approval by all countries, the regulatory policy under Common regulation would constitute a Pareto improvement. The CRA would then be maximizing a weighted average of national welfare subject to the political participation constraint, $W_{i}\left(\mathbf{Q}, \mathbf{u}_{i}\right) \geq W_{i}\left(\mathbf{Q}^{S}, \mathbf{u}_{i}^{S}\right), i=1,2$. Welfare losses arise under Common regulation only if $(i)$ the CRA does not have to worry about member state

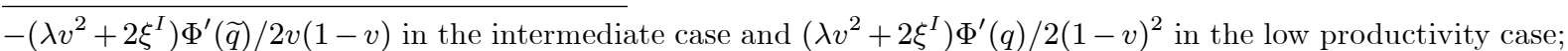
compare $(\overline{8})$ and (11). 
participation constraints or (ii) whoever holds the veto right in each country pursues a different objective than national welfare maximization. The European Union constitutes an example of multi-national political cooperation with limited veto rights. Participation in the EU is voluntary, but the member states have delegated important policy decisions to EU authorities, energy policy being a prominent example. Note also that Proposition 1 has policy ramifications also under voluntary participation. Even if the countries have agreed to a common regulatory agency, welfare is higher the more balanced is the political influence of the member states. ${ }^{11}$

I have assumed proportional and non-discriminatory (symmetric) regulation as a means to curbing the problem of transfer exploitation. Yet, it appears not to have any real effect here. If political power is perfectly balanced $\left(\mu_{1}=\mu_{2}=1 / 2\right)$, the common regulatory agency maximizes aggregate welfare even with full discretion over transfers and incentives. However, the importance of proportionality and non-discrimination depends not only on the distribution $\left(\mu_{1}, \mu_{2}\right)$ of political influence, but also on the distribution $\left(\triangle S_{1}, \triangle S_{2}\right)$ of the gains from integration. Assume that the gains from integration are symmetric, i.e. $\triangle S_{1}=\triangle S_{2}=\triangle S$. Then, the perceived marginal benefit of integration equals

$$
2 P_{i}^{\prime}(q)\left(\mu_{1} \triangle S_{1}+\mu_{2} \triangle S_{1}\right)=2 P_{i}^{\prime}(q)\left(\mu_{1}+\mu_{2}\right) \triangle S=2 P_{i}^{\prime}(q) \triangle S
$$

under symmetric regulation, which is completely independent of the distribution of political power. Under symmetric gains from trade and under the assumption of symmetric policies, welfare maximization results even under simple majority rule. Welfare maximization would not occur if the CRA could discriminate between the countries. Under simple majority rule $\left(\mu_{i}=\right.$ 1 ), and for any domestic regulatory policy $\mathbf{q}_{i}$, the country in power would push maintenance spending abroad as high as possible (raise $\mathbf{q}_{j}$ up to the point at which $W_{j}\left(\mathbf{Q}, \mathbf{u}_{j}\right)=W_{j}\left(\mathbf{Q}^{S}, \mathbf{u}_{j}^{S}\right)$ under voluntary participation) because the perceived social costs of transfers abroad is zero. Symmetry arising from proportionality and non-discrimination forces the CRA to internalize parts of the social costs of transfers abroad. Under symmetric gains from integration, there is full internalization.

Laffont and Pouyet (2003) analyse the costs and benefits of decentralized policies in a multinational procurement model. Unlike in the present paper where voters are distinguished by the country they reside in (interjurisdictional heterogeneity), Laffont and Pouyet (2003) assume that voters either are shareholders or non-shareholders (intrajurisdictional heterogeneity). Under centralized procurement the buyer places more weight on firm rent than consumer surplus if shareholders are in overall majority, but cares nothing about firm rent if shareholders are in overall minority. A main result is that centralized procurement welfare dominates decentralized procurement if and only if votes are asymmetrically distributed between shareholders and nonshareholders. This is the exact opposite of Proposition 1. Laffont and Pouyet's (2003) result can be traced to a peculiar specification of the objective function of the centralized buyer. Under

\footnotetext{
${ }^{11}$ Bargaining over regulatory policies would maximize aggregate welfare if the NRAs had access to productivity dependent lump-sum transfers. Typically, regulators have limited possibilities for side transfers. Side transfers among system operators (typically in the form of cross-border congestion rents) will not do as a substitute because they might interfere with incentive compatibility and participation constraints.
} 
shareholder majority, the weight of consumer surplus relative to firm rent by assumption is higher the larger is shareholder majority. Consumer surplus and firm rent have near equal weights in the limit when almost everybody is a shareholder, in which case the centralized buyer acts almost as the benevolent social planner.

Whether political conflict in transmission regulation can best be described as "cross-border" or "cross-ownership" depends on who owns and manages the grid. With state-owned national system operators, as in Norway, Sweden and Denmark, it makes more sense to think in terms of cross-border conflicts because all citizens have identical stakes in the national firm. Transmission regulation is more susceptible to political influence by shareholders in Finland where the system operator, Fingrid, is partially privately owned.

Common regulation versus Integration The previous section analysed the costs and benefits of creating a common regulatory agency versus maintaining as structure of national regulatory agencies, holding fixed the structure of national system operators. This section instead analyses the costs of benefits of having a common system operator versus national system operators, fixing the regulatory structure. The question of whether a common system operator (CSO) is better than two national system operators (NSOs) is a question of whether the informational rent externalities are positive or negative under the different structures.

Assume that the common regulatory agency (CRA) wants to implement the symmetric policy $\mathbf{q}=(\bar{q}, \widehat{q}, \widetilde{q}, \underline{q})$, where $\mathbf{q}$ satisfies the monotonicity constraint $\max \{\bar{q} ; \widehat{q}\} \geq \min \{\widetilde{q} ; \underline{q}\}$. The CRA can implement $\mathbf{q}$ both under a single CSO and when system operation is split between two NSOs by applying an appropriate menu of transfers. ${ }^{12}$ Expected network reliability and social maintenance costs are the same irrespective of how system operation is managed. The optimal structure of system operation then boils down to minimizing expected operator rent. Merging the two NSOs into a CSO is a cost efficient way of implementing $\mathbf{q}$ if and only if

$$
v^{2}(\Phi(\underline{q})+\max \{\Phi(\widetilde{q}) ; \Phi(\underline{q})\})+2 v(1-v) \Phi(\underline{q})<2 v^{2} \Phi(\widetilde{q})+2 v(1-v) \Phi(\underline{q})
$$

in which case the expected operator rent is lower with a CSO than two NSOs.

Merging system operation is profitable if $\widetilde{q}>\underline{q}$ and unprofitable if $\widetilde{q}<\underline{q}$. To understand this result, assume that both networks are of high productivity $(\beta=\{\bar{\beta}, \bar{\beta}\})$. An understatement of productivity from $\bar{\beta}$ to $\underline{\beta}$ by NSO $j$ affects the regulatory policies of both NSOs owing to the interdependence of marginal network reliability. This informational rent externality equals $\Phi(\underline{q})-\Phi(\widetilde{q})$ and is negative if $\widetilde{q}>\underline{q}$, but positive if $\widetilde{q}<\underline{q}$. Thus, merging system operation into a CSO is optimal whenever the informational rent externalities are negative, while splitting system operation between two NSOs is optimal under positive informational rent externalities.

The sign of the informational rent externalities depends crucially on whether the network displays complementarities or substitutability. The network externality is negative under com-

\footnotetext{
${ }^{12}$ The appropriate transfers to the $\operatorname{CSO}$ are $2 \bar{t}=2 \psi(\bar{q} / \bar{\beta})+\Phi(\underline{q})+\max \{\Phi(\widetilde{q}) ; \Phi(\underline{q})\}, \widehat{t}+\widetilde{t}=\psi(\widehat{q} / \bar{\beta})+\psi(\widetilde{q} / \underline{\beta})+\Phi(\underline{q})$ and $2 \underline{t}=2 \psi(\underline{q} / \underline{\beta})$. The appropriate transfers to each NSO are $\bar{t}=\psi(\bar{q} / \bar{\beta})+\Phi(\widetilde{q}), \widehat{t}=\psi(\widehat{q} / \bar{\beta})+\Phi(\underline{q}), \widetilde{t}=\psi(\widetilde{q} / \underline{\beta})$ and $\underline{t}^{I}=\psi(\underline{q} / \underline{\beta})$.
} 
plementarity: Lower productivity in network $i$ triggers a reduction in maintenance spending everywhere because the virtual marginal maintenance cost goes up in network $i$ and the marginal benefit of maintenance spending falls in network $j$. The rent externality is negative because informational rent is increasing in maintenance spending. By merging system operation into a single CSO, the regulatory agency forces the networks to internalize the negative rent externality by means of cross-subsidization:

Proposition 2 Assume that the network displays complementarities $\left(P_{i j}^{\prime \prime}>0\right.$ for all $\left.q\right)$. Then, the common regulatory agency prefers a common system operator to two national system operators. If also political influence of the two countries is balanced $\left(\mu_{1} \approx 1 / 2\right)$, so that the common regulatory agency internalizes most of the gains from market integration, Integration welfare dominates both Common regulation and Separation.

The proof is in the Appendix.

Negative informational rent externalities under quality complementarity render Integration better than Common regulation from the regulator's point of view. The regulator acts as the benevolent social planner when political power is balanced. In that case, Integration is the socially optimal network structure. ${ }^{13}$

Based on the above results, it might be tempting to draw the conclusion that network substitutability gives rise to positive network externalities. But this is not always true. Lower productivity in network $i$ implies a reduction in optimal maintenance spending in network $i$ under all network structures because the virtual marginal maintenance cost of network $i$ is higher the lower is the productivity of that network. The quality reduction in network $i$ tends to increase maintenance spending in network $j$ under quality substitutability. However, the ability of the CSO to understate performance of the entire network drives up the virtual marginal maintenance cost for the lowest productivity network under Integration. A higher marginal cost tends to lower optimal maintenance spending in the lowest productivity network. If the social cost of informational rent $(\lambda v)$ is high, the cost effect dominates the substitution effect and so negative network externalities persist under Integration also under quality substitutability: $\widetilde{q}^{I}>\underline{q}^{I}$. On the other hand, if the social cost of informational rent is low, Integration generates positive network externalities $\left(\underline{q}^{I}>\widetilde{q}^{I}\right)$ :

Proposition 3 Under network substitutability $\left(P_{i j}^{\prime \prime}<0\right.$ for all $\left.q\right)$ and if the social cost of informational rent $(\lambda v)$ is low, informational rent externalities are positive under Integration $\left(\widetilde{q}^{I}<\underline{q}^{I}\right)$. The common regulatory agency then prefers to divide system operation between two national system operators instead of having a common system operator. If also network quality

\footnotetext{
${ }^{13}$ Integration is optimal among all network structures in Table 1 under the conditions of Proposition 2. For $\mu_{i} \approx 1 / 2$, Integration welfare dominates even Common agency because the regulatory policy $\mathbf{q}^{I}$ then is close to the socially optimal, conditionally on there being a single CSO.
} 
is a normal good and political influence of the two countries is balanced $\left(\mu_{1} \approx 1 / 2\right)$, Common regulation welfare dominates Integration as well as Separation.

The proof is in the Appendix.

The common system operator internalizes the positive rent externality by coordinating performance in all parts of the network. This exercise of agency power drives up the informational rent under Integration. The common regulatory agency mitigates agency power by splitting system operation among a set of national system operators and setting up a dominant strategy incentive structure.

The costs and benefits of having a common system operator (CSO) versus maintaining two national system operators (NSOs) resemble the costs and benefits of monopoly versus duopoly in an unregulated market. The monopoly exercises more market power than the duopoly. Yet, monopoly is better provided the monopoly exhibits sufficient cost synergies to offset the negative effects of market power. Owing to its monopoly on information about network productivity, the CSO exercises more agency power than two separate NSOs. Nonetheless, a CSO is optimal provided the cost synergies arising from merging system operation are strong enough. In the present context, these cost synergies stem from cross-subsidization. With a single system operator, the regulator has to worry about aggregate incentives, whereas the incentive and participation constraints of each NSO constrain the set of feasible regulatory policies when there are more than one system operator.

Dana (1993) is the first to emphasize the importance of informational rent externalities for the optimal market structure of a regulated industry. Dana exclusively focuses on negative rent externalities as a motivation for granting monopoly rights and labeled them informational economies of scope (in the present context, the equivalent of Dana's assumption would be independence: $P_{12}=P_{21}=0$ for all $q$ ). Positive rent externalities would correspond to informational diseconomies of scope.

Serevinov (2008) studies optimal organization of production in a model with a single principal and two agents. He shows that the optimal mode of organization depends on whether the value of information is superadditive or subadditive, which here corresponds to positive versus negative informational rent externalities. In his analysis Serevinov (2008) establishes the link between the degree of substitutability/complementarity of inputs and additivity. Information is subadditive if inputs are weak complements or weak substitutes (i.e. in the present context, the condition is $\left|P_{i j}\right| /\left|P_{i i}\right|<z$ for all $q$ and some $\left.0<z \leq 1\right)$ and it is superadditive if inputs are asymmetric and inputs are strong complements or substitutes. ${ }^{14}$ The present paper extends Serevinov (2008) by studying also the optimal number of principals. It complements his analysis by bringing out the link between informational externalities and the social cost of informational rent. Quality substitutability alone tends to generate positive rent externalities, but the cost of informational rent pulls in the opposite direction. If the social cost is high, informational rent externalities

\footnotetext{
${ }^{14}$ Serevinov's (2008) result that splitting production between several agents can be optimal under complementarity relies more on asymmetry than strong complementarity. Under symmetry, as in the present model, a single agent is optimal no matter the degree of complementarity.
} 
are positive under the single-agent structure, and splitting system operation between two NSOs need not be optimal even under strong quality substitutability.

\section{Conclusion}

No network governance structure does uniformly better and no governance structure performs uniformly worse than all others in this model. Rather, optimal network structure depends on $(i)$ how well the common regulatory agency balances the interests of the different member states; (ii) how the gains from energy market integration vary across the member states; (iii) the characteristics of the network (substitutability versus complementarity); (iv) the social cost of operator rent.

Having a common regulatory agency is better from a welfare perspective than maintaining national regulatory agencies on the proviso that political influence is sufficiently balanced across the member states in the common regulatory agency. With an equal distribution of political power, no member state can exert enough influence over regulatory policy to tilt it in one's own favour. The importance of balanced political influence is well understood by the European Union. The newly established Agency for the Cooperation of Energy Regulators (ACER) is furnished with the task of coordinating transmission regulation across the EU member states and deciding on the terms and conditions for access to cross-border infrastructure in case of national disagreement. ACER's Board of Regulators reside under instructions to act independently from any government of a member state. Only one representative per member state may be admitted to the Board of Regulators, and the board members have one vote each (EU, 2009a).

With balanced political influence, the preferences of the regulator are aligned with those of the benevolent social planner. Under those conditions, a common system operator is socially optimal under network complementarity, whereas splitting network operation is socially optimal under network substitutability and provided the social cost of operator rent is not too high. Whether a network displays complementarities or substitutability depends on network topology. In a radial network, energy flows from production node A to consumption node B through a sequence of interconnections, where the interconnector with the smallest capacity determines the capacity of the entire network. The radial network displays a high degree of complementarity because the value of expanding capacity in any single part of the network increases the higher is capacity in other parts of the network. In a meshed network, energy flows from production node A to consumption node B through a fine web of interconnected transmission lines. Any single interconnection is less important the higher is the capacity of alternative interconnections. The meshed network therefore displays a high degree of substitutability.

Rent externalities stemming from network substitutability may have exacerbated the capacity problems of the Oslofjord cable between southern Norway and southern Sweden described in the Introduction. In May 2008, precisely when the Oslofjord cable broke down, the NorNed cable between southern Norway and the Netherlands went operational. The longest submarine power cable in the world, NorNed was a prestige project for its owners Statnett and TenneT (the 
dutch system operator). Reduced export capacity from Norway to Sweden over the Oslofjord cable suddenly made NorNed immensely profitable: The resulting price drop in southern Norway raised the value of electricity trade between the Netherlands and southern Norway. Being the only transmission line directly connecting the two markets, NorNed could sell its transmission capacity at a vastly higher price than projected. Owning the Oslofjord cable as well as half of NorNed, Statnett probably internalized part of the positive rent externality on NorNed of reduced capacity on the Oslofjord cable. Had NorNed instead been fully owned by TenneT, or had the interconnection broken down on the Swedish side, the net value to the owner of repairing the Oslofjord cable would have been higher.

I have conducted the analysis within a complete contracting framework. All necessary policy coordination takes place at the level of regulation under complete contracting: There is no role for delegating tasks to the system operator. While a fitting description of capacity regulation, the assumption that the regulator can contract on all contingencies regarding day-to-day system operation is unlikely to hold. Contractual incompleteness speaks in favour of establishing a common system operator to the extent multi-national energy markets require detailed coordination of cross-border system operation.

\section{Appendix}

\section{Proof of Lemma 1}

By the boundary condition $(\mathrm{BC})$ all possible maxima of $W_{1}(\mathbf{Q}, \mathbf{0})+W_{2}(\mathbf{Q}, \mathbf{0})$ by necessity are contained in $[0, k]^{8}$. Maximization of a continuous function on a compact set yields an optimum. Concavity of $P$ and strict convexity of $\psi$ render aggregate welfare strictly concave, hence the solution is unique. The solution is interior by the assumption that $P_{i}^{\prime}\left(0, q_{j}\right)>0$ for all $q_{j} \geq 0$ and $\psi^{\prime}(0)=0$. Symmetry of $P, \lambda$ and $\psi$ render the solution symmetric. Thus, the first-order conditions (focs) given by (2) characterize the unique solution. Define $\left(q_{1}^{f b}(\beta), q_{2}^{f b}(\beta)\right)$ as the implicit solution to $P_{1}^{\prime}\left(q_{1}^{f b}, q_{2}^{f b}\right)\left(\triangle S_{1}+\triangle S_{2}\right)=(1+\lambda) \psi^{\prime}\left(q_{1}^{f b} / \beta_{1}\right) / \beta_{1}$ and $P_{2}^{\prime}\left(q_{1}^{f b}, q_{2}^{f b}\right)\left(\triangle S_{1}+\right.$ $\left.\triangle S_{2}\right)=(1+\lambda) \psi^{\prime}\left(q_{2}^{f b} / \beta_{2}\right) / \beta_{2}$. Straightforward differentiation yields:

$\frac{d q_{i}^{f b}}{d \beta_{j}}=\frac{P_{i j}^{\prime \prime}\left(\triangle S_{1}+\triangle S_{2}\right)(1+\lambda)\left(q_{j}^{f b} \psi_{j j}^{\prime \prime}+\psi_{j}^{\prime} / \beta_{j}\right)}{\left(P_{11}^{\prime \prime} P_{22}^{\prime \prime}-P_{12}^{\prime \prime} P_{21}^{\prime \prime}\right)\left(\triangle S_{1}+\triangle S_{2}\right)^{2}-(1+\lambda)\left(P_{11}^{\prime \prime} \psi_{22}^{\prime \prime}+P_{22}^{\prime \prime} \psi_{11}^{\prime \prime}\right)\left(\triangle S_{1}+\triangle S_{2}\right)+(1+\lambda)^{2} \psi_{11}^{\prime \prime} \psi_{22}^{\prime \prime}}$

where $\psi_{i}^{\prime}=\psi^{\prime}\left(q_{i}^{f b} / \beta_{i}\right) / \beta_{i}$ and $\psi_{i i}^{\prime \prime}=\psi^{\prime \prime}\left(q_{i}^{f b} / \beta_{i}\right) / \beta_{i}^{2}$. By concavity of $P$ and strict convexity of $\psi$, the denominator is positive, so $d q_{i}^{f b} / d \beta_{j}>0$ if $P_{j i}^{\prime \prime}>0$, but $d q_{i}^{f b} / d \beta_{j}<0$ if $P_{j i}^{\prime \prime}<0$.

\section{Proof of Lemma 2}

Assume that both NRAs have committed to dominant strategy implementable direct (DSID) 
contracts. Consider the Lagrangian

$$
L_{i}^{S}\left(\mathbf{Q}, \chi_{i}, \xi_{i}, \boldsymbol{\alpha}_{i}\right)=W_{i}^{S}(\mathbf{Q})+\chi_{i}\left(\bar{q}_{i}-\widetilde{q}_{i}\right)+\xi_{i}\left(\widehat{q}_{i}-\underline{q}_{i}\right)+\boldsymbol{\alpha}_{i} \mathbf{q}_{i},
$$

where $\chi_{i} \geq 0$ and $\xi_{i} \geq 0$ are the Kuhn-Tucker multipliers associated with $\bar{q}_{i} \geq \widetilde{q}_{i}$ and $\widehat{q}_{i} \geq \underline{q}_{i}$, and $\boldsymbol{\alpha}_{i}=\left(\bar{\alpha}_{i}, \widehat{\alpha}_{i}, \widetilde{\alpha}_{i}, \underline{\alpha}_{i}\right) \geq \mathbf{0}$ are the Kuhn-Tucker multipliers associated with non-negative quality, $\mathbf{q}_{i} \geq \mathbf{0}$. Concavity of $P$ plus strict convexity of $\psi$ and $\Phi$ render $W_{i}^{S}$ strictly concave in $\mathbf{q}_{i}$. Strict concavity of $W_{i}^{S}$ and linearity of the constraints render $L_{i}^{S}$ strictly concave in $\mathbf{q}_{i}$. Thus, every solution $\left(\mathbf{q}_{i}^{S}, \chi_{i}^{S}, \xi_{i}^{S}\right), \boldsymbol{\alpha}_{i}^{S}, i=1,2$, to the first-order conditions $\partial L_{i}^{S} / \partial \mathbf{q}_{i}=\mathbf{0}$ and associated complementary slackness conditions constitutes an equilibrium of this game.

Define $\Omega_{i}=\left(\mathbf{q}_{i}, \chi_{i}, \xi_{i}\right), \Omega=\left(\Omega_{1}, \Omega_{2}\right), l_{i}(\Omega)=\left(\boldsymbol{\alpha}_{i}-\partial L_{i}^{S} / \partial \mathbf{q}_{i}, \bar{q}_{i}-\widetilde{q}_{i}, \widehat{q}_{i}-\underline{q}_{i}\right)$ and $l(\Omega)=$ $\left(l_{1}(\Omega), l_{2}(\Omega)\right)$. By construction, every equilibrium $\left(\mathbf{q}_{i}^{S}, \chi_{i}^{S}, \xi_{i}^{S}\right), \boldsymbol{\alpha}_{i}^{S}, i=1,2$, of the game is a solution to the complementary problem:

Find $\Omega \geq 0$ such that $l(\Omega) \geq 0, \Omega_{i} l_{i}(\Omega)=0, i=1,2$.

Conversely, every solution to (12) characterizes an equilibrium of the game with $\boldsymbol{\alpha}_{i}$ appropriately defined. Thus, there are exactly as many equilibria of the game as there are solutions to (12).

The mapping $l$ is continuously differentiable by the assumption that $P_{i}^{\prime}, \psi^{\prime}$ and $\Phi^{\prime}$ are continuously differentiable. Thus, (12) has a unique solution if $(i)$ every solution to (12) is element of a compact set; (ii) $l$ satisfies an appropriate regularity condition; and (iii) the Jacobian of $l$, eliminating rows and columns with elements of zero, is positive at all solutions to (12); see Kolstad and Mathiesen (1987).

Condition $(i)$ : For all $\widetilde{q}_{1}>k>0$,

$$
\begin{aligned}
\widetilde{\alpha}_{1}-\partial L_{1}^{S} / \partial \widetilde{q}_{1} & =\chi_{1}+v(1-v)\left[(1+\lambda)\left(\psi^{\prime}\left(\widetilde{q}_{1} / \underline{\beta}\right) / \underline{\beta}+\frac{v}{1-v} \frac{\lambda}{1+\lambda} \Phi^{\prime}\left(\widetilde{q}_{1}\right)\right)-P_{1}^{\prime}\left(\widetilde{q}_{1}, \widehat{q}_{2}\right) \triangle S_{1}\right] \\
& >v(1-v)\left((1+\lambda) \psi^{\prime}\left(\widetilde{q}_{1} / \underline{\beta}\right) / \underline{\beta}-P_{1}^{\prime}\left(\widetilde{q}_{1}, \widehat{q}_{2}\right)\left(\triangle S_{1}+\triangle S_{2}\right)\right)>0
\end{aligned}
$$

where the second inequality follows from (BC). By necessity, then, every solution to (12) satisfies $\widetilde{q}_{1} \in[0, k]$. For all $\bar{q}_{1}>k \geq \widetilde{q}_{1}$,

$$
\bar{\alpha}_{1}-\partial L_{1}^{S} / \partial \bar{q}_{1}=v^{2}\left((1+\lambda) \psi^{\prime}\left(\bar{q}_{1} / \bar{\beta}\right) / \bar{\beta}-P_{1}^{\prime}\left(\bar{q}_{1}, \bar{q}_{2}\right) \triangle S_{1}\right)-\chi_{1}
$$

which is strictly positive by $(\mathrm{BC})$ and $\chi_{1}\left(\bar{q}_{1}-\widetilde{q}_{1}\right)=0$. By necessity every solution to (12) 
satisfies even $\bar{q}_{1} \leq k$. Suppose $\bar{q}_{1}=0$. Then

$$
\bar{\alpha}_{1}-\partial L_{1}^{S} / \partial \bar{q}_{1}=-v^{2} P_{1}^{\prime}\left(0, \bar{q}_{2}\right) \triangle S_{1}-\chi_{1}<0
$$

by the assumptions that $P_{1}^{\prime}\left(0, q_{2}\right)>0$ for all $q_{2} \geq 0$ and $\psi^{\prime}(0)=0$. Thus, $\bar{q}_{1} \in(0, k]$. By analogous arguments, $\underline{q}_{1} \in[0, k]$ and $\widehat{q}_{1} \in(0, k]$. Consider next the multiplier $\chi_{1}$. Since $\bar{q}_{1}>0$, $\bar{\alpha}_{1}-\partial L_{1}^{S} / \partial \bar{q}_{1}=0$ and therefore

$$
\chi_{1}=v^{2}\left[(1+\lambda) \psi^{\prime}\left(\bar{q}_{1} / \bar{\beta}\right) / \bar{\beta}-P_{1}^{\prime}\left(\bar{q}_{1}, \bar{q}_{2}\right) \triangle S_{1}\right] \leq \max _{q \in[0, k]^{2}} v^{2}\left[(1+\lambda) \psi^{\prime}\left(q_{1} / \bar{\beta}\right) / \bar{\beta}-P_{1}^{\prime}(q) \triangle S_{1}\right] .
$$

Thus, $\chi_{1} \geq 0$ is bounded from above. Analogously, $\xi_{1} \geq 0$ is bounded from above. Similarly, $\Omega_{2}$ is contained in a compact and convex set. This concludes the proof that every possible solution to (12) is element of a compact (and convex) set.

Condition (ii): The regularity condition states at every solution $\Omega$ to (12), $\Omega_{i}=0$ implies $l_{i}(\Omega)>0$. Regularity is a generic property and satisfied for almost all parameter values.

Condition (iii): It is easy to verify that the Jacobian of $l(\Omega)$ has strictly positive leading principal minors for all $\Omega \geq 0$ and therefore is positive definite.

The complementary problem (12) has a unique solution and there exists a unique equilibrium of the game for generic parameter values. To verify that this solution is given by (5), it is sufficient to check that (5) satisfies $\mathbf{Q}^{S}>\mathbf{0}, \bar{q}_{i}^{S}>\widetilde{q}_{i}^{S}$ and $\widehat{q}_{i}^{S}>\underline{q}_{i}^{S}$. The assumptions $P_{1}^{\prime}\left(0, q_{2}\right)>0$ for all $q_{2} \geq 0, P_{2}^{\prime}\left(q_{1}, 0\right)>0$ for all $q_{1} \geq 0$ and $\psi^{\prime}(0)=\Phi^{\prime}(0)=0$ render the solution interior $\left(\mathbf{Q}^{S}>0\right)$. I finally demonstrate that $\bar{q}_{i}^{S}>\widetilde{q}_{i}^{S}$ and $\widehat{q}_{i}^{S}>\underline{q}_{i}^{S}$. Define the generalized (strictly convex) virtual maintenance cost

$$
\begin{aligned}
c\left(q_{i} ; \beta_{i}\right) & =(1+\lambda)\left[\frac{\beta_{i}-\underline{\beta}}{\bar{\beta}-\underline{\beta}} \psi\left(q_{i} / \bar{\beta}\right)+\frac{\bar{\beta}-\beta_{i}}{\bar{\beta}-\underline{\beta}}\left(\psi\left(q_{i} / \underline{\beta}\right)+\frac{v}{1-v} \frac{\lambda}{1+\lambda} \Phi\left(q_{i}\right)\right)\right] \\
& =(1+\lambda)\left[\psi\left(q_{i} / \bar{\beta}\right)+\frac{\bar{\beta}-\beta_{i}}{\bar{\beta}-\underline{\beta}}\left(1+\frac{v}{1-v} \frac{\lambda}{1+\lambda}\right) \Phi\left(q_{i}\right)\right],
\end{aligned}
$$

where I have used $\Phi\left(q_{i}\right)=\psi\left(q_{i} / \underline{\beta}\right)-\psi\left(q_{i} / \bar{\beta}\right)$. Let $c_{i}^{\prime}\left(q_{i} ; \beta_{i}\right)=\partial c\left(q_{i} ; \beta_{i}\right) / \partial q_{i}$ and $c_{i i}^{\prime \prime}\left(q_{i} ; \beta_{i}\right)=$ $\partial^{2} c\left(q_{i} ; \beta_{i}\right) / \partial q_{i}^{2}>0$. Define $q^{S}\left(\beta_{i}, \beta_{j}\right)$ as the implicit solution to $P_{i}^{\prime}\left(q^{S}\right) \triangle S_{i}=c_{i}^{\prime}\left(q_{i}^{S} ; \beta_{i}\right), i=1,2$. Now, $\bar{q}_{i}^{S}-\widetilde{q}_{i}^{S}=\int_{\underline{\beta}}^{\bar{\beta}}\left[\partial q_{i}^{S}\left(\beta_{i}, \bar{\beta}\right) / \partial \beta_{i}\right] d \beta_{i}>0$ because

$$
\frac{\partial q_{i}^{S}\left(\beta_{i}, \beta_{j}\right)}{\partial \beta_{i}}=\frac{(1+\lambda)\left(1+\frac{v}{1-v} \frac{\lambda}{1+\lambda}\right) \Phi^{\prime}\left(q_{i}^{S}\right)\left(\partial^{2} c_{j j}^{\prime \prime}-P_{j j}^{\prime \prime} \triangle S_{j}\right) /(\bar{\beta}-\underline{\beta})}{\left(P_{11}^{\prime \prime} P_{22}^{\prime \prime}-P_{12}^{\prime \prime} P_{21}^{\prime}\right) \triangle S_{1} \triangle S_{2}-P_{11}^{\prime \prime} c_{22}^{\prime \prime} \triangle S_{1}-P_{22}^{\prime \prime} c_{11}^{\prime \prime} \triangle S_{2}+c_{11}^{\prime \prime} c_{22}^{\prime \prime}}>0 .
$$

By implication even $\widehat{q}_{i}^{S}-\underline{q}_{i}^{S}=\int_{\underline{\beta}}^{\bar{\beta}}\left[\partial q_{i}^{S}\left(\beta_{i}, \underline{\beta}\right) / \partial \beta_{i}\right] d \beta_{i}>0$. 
Having established existence and uniqueness, I turn now to the comparative statics of the equilibrium contracts. Consider first the problem of overall under-spending $\left(P\left(q^{S}\right)<P\left(q^{f b}\right)\right)$. The proof is in two steps. First, I consider under-spending as a failure to internalize trade externalities, ignoring the effects of informational rent. I then show that informational rent adds an additional distortion under Separation. Define $z^{f b}(\theta)$ as the implicit solution to $P_{i}^{\prime}\left(z^{f b}\right)\left(\triangle S_{i}+\right.$ $\left.\theta \triangle S_{j}\right)=\psi^{\prime}\left(z_{i}^{f b} / \beta_{i}\right) / \beta_{i}, i, j=1,2, i \neq j$. By construction $z^{f b}(1)=q^{f b}$, and $z_{i}^{f b}(0)$ is the equilibrium under Separation when the NRAs do not take the social cost of informational rent into account. Differentiation yields:

$\frac{d z_{i}^{f b}}{d \theta}=\frac{P_{i}^{\prime}\left(\psi_{j j}^{\prime \prime}-P_{j j}^{\prime \prime}\left(\theta \triangle S_{i}+\triangle S_{j}\right)\right) \triangle S_{j}+P_{j}^{\prime} P_{i j}^{\prime \prime}\left(\triangle S_{i}+\theta \triangle S_{j}\right) \triangle S_{i}}{\left(P_{i i}^{\prime \prime}\left(\triangle S_{i}+\theta \triangle S_{j}\right)-\psi_{i i}^{\prime \prime}\right)\left(P_{j j}^{\prime \prime}\left(\theta \triangle S_{i}+\triangle S_{j}\right)-\psi_{j j}^{\prime \prime}\right)-P_{j i}^{\prime \prime}\left(\theta \triangle S_{i}+\triangle S_{j}\right) P_{i j}^{\prime \prime}\left(\triangle S_{i}+\theta \triangle S_{j}\right)}$,

which is of ambiguous sign. Total differentiation of $P\left(z^{f b}(\theta)\right)$ yields after simplification and using symmetry $\left(P_{j i}^{\prime \prime}=P_{i j}^{\prime \prime}\right)$ :

$\frac{d P}{d \theta}=\frac{\sum_{i \neq j=1,2}\left(\left(P_{i}^{\prime}\right)^{2} \psi_{j j}^{\prime \prime} \triangle S_{j}+P_{i}^{\prime}\left(P_{j}^{\prime} P_{i j}^{\prime \prime}-P_{i}^{\prime} P_{j j}^{\prime \prime}\right)\left(\theta \triangle S_{i}+\triangle S_{j}\right) \triangle S_{j}\right)}{\left(P_{i i}^{\prime \prime}\left(\triangle S_{i}+\theta \triangle S_{j}\right)-\psi_{i i}^{\prime \prime}\right)\left(P_{j j}^{\prime \prime}\left(\theta \triangle S_{i}+\triangle S_{j}\right)-\psi_{j j}^{\prime \prime}\right)-P_{j i}^{\prime \prime}\left(\theta \triangle S_{i}+\triangle S_{j}\right) P_{i j}^{\prime \prime}\left(\triangle S_{i}+\theta \triangle S_{j}\right)}$,

which is positive under condition (NG). Hence, $P\left(q^{f b}\right)>P\left(z^{f b}(0)\right)$. Consider next the effect of informational rent. Differentiate $q_{i}^{S}$ with respect to $v$ :

$$
\frac{d q_{i}^{S}}{d v}=\frac{-\left(c_{j j}^{\prime \prime}-P_{j j}^{\prime \prime} \triangle S_{j}\right) \partial c_{i}^{\prime} / \partial v-P_{i j}^{\prime \prime} \triangle S_{i} \partial c_{j}^{\prime} / \partial v}{\left(P_{11}^{\prime \prime} P_{22}^{\prime \prime}-P_{12}^{\prime \prime} P_{21}^{\prime \prime}\right) \triangle S_{1} \triangle S_{2}-\left(P_{11}^{\prime \prime} c_{22}^{\prime \prime} \triangle S_{1}+P_{22}^{\prime \prime} c_{11}^{\prime \prime} \triangle S_{2}\right)+c_{11}^{\prime \prime} c_{22}^{\prime \prime}},
$$

which can be positive or negative. Total differentiation of $P\left(q^{S}\right)$ with respect to $v$ yields after simplification and using symmetry $\left(P_{j i}^{\prime \prime}=P_{i j}^{\prime \prime}\right)$ :

$$
\frac{d P\left(q^{S}\right)}{d v}=\frac{-\sum_{i \neq j=1,2}\left(P_{i}^{\prime} c_{j j}^{\prime \prime} \partial c_{i}^{\prime} / \partial v+\left(P_{i}^{\prime} P_{j i}^{\prime \prime}-P_{j}^{\prime} P_{i i}^{\prime \prime}\right) \triangle S_{i} \partial c_{j}^{\prime} / \partial v\right)}{\left(P_{11}^{\prime \prime} P_{22}^{\prime \prime}-P_{12}^{\prime \prime} P_{21}^{\prime \prime}\right) \triangle S_{1} \triangle S_{2}-\left(P_{11}^{\prime \prime} c_{22}^{\prime \prime} \triangle S_{1}+P_{22}^{\prime \prime} c_{11}^{\prime \prime} \triangle S_{2}\right)+c_{11}^{\prime \prime} c_{22}^{\prime \prime}} .
$$

Under condition $(\mathrm{NG}), d P\left(q^{S}\right) / d v \leq 0$. Since $q_{i, v=0}^{S}=z_{i}^{f b}(0), P\left(q^{S}\right) \leq P\left(z^{f b}(0)\right)$. Under condition (NG), therefore, $P\left(q^{S}\right) \leq P\left(z^{f b}(0)\right)<P\left(q^{f b}\right)$.

To see that NSO 1 overinvests relative to NSO 2 under Separation when $\triangle S_{1}>\triangle S_{2}$, fix aggregate quality at $X$ and implicitly define $x_{1}(\kappa)$ by

$$
\frac{P_{1}^{\prime}\left(x_{1}, X-x_{1}\right)}{P_{2}^{\prime}\left(x_{1}, X-x_{1}\right)} \kappa=\frac{c_{1}^{\prime}\left(x_{1} ; \beta_{1}\right)}{c_{2}^{\prime}\left(X-x_{1} ; \beta_{2}\right)}
$$

where $\kappa \in\left[1, \triangle S_{1} / \triangle S_{2}\right]$. Under the assumption of two NSOs, the second-best optimal distribu- 
tion of quality is $\left(x_{1}(1), x_{2}(1)\right)$ because this is the point at which the marginal rate of substitution equals the (virtual) marginal technical rate of substitution, whereas $\left(x_{1}\left(\triangle S_{1} / \triangle S_{2}\right), x_{2}\left(\triangle S_{1} / \triangle S_{2}\right)\right)=$ $\left(q_{1}^{S}(\beta), q_{2}^{S}(\beta)\right)$. Differentiate and substitute in $\kappa=P_{2}^{\prime} c_{1}^{\prime} / c_{2}^{\prime} P_{1}^{\prime}$ to get

$$
x_{1}^{\prime}(\kappa)=\frac{\left(P_{1}^{\prime}\right)^{2}\left(c_{2}^{\prime}\right)^{2}}{\sum_{i \neq j=1,2}\left(P_{1}^{\prime} P_{2}^{\prime} c_{i}^{\prime} c_{j j}^{\prime \prime}+\left(P_{i}^{\prime} P_{j i}^{\prime}-P_{j}^{\prime} P_{i i}^{\prime \prime}\right) c_{1}^{\prime} c_{2}^{\prime}\right)},
$$

which is strictly positive under condition (NG). Thus, $\triangle S_{1}>\triangle S_{2}$ implies relative overinvestment in $1\left(q_{1}^{S}(\beta)>x_{1}(1)\right)$ and under-spending in $2\left(q_{2}^{S}(\beta)<x_{2}(1)\right)$ under Separation.

\section{The relevance of dominant strategy implementable direct (DSID) mechanisms under Separation}

The restriction to dominant strategy implementable direct (DSID) mechanisms is without loss of generality in the sense that every dominant strategy Perfect Bayesian Equilibrium of a regulation game with general message space (defined below), can equivalently be represented as the equilibrium of a game where both regulators have committed to offering direct DSID mechanisms.

Consider a regulatory game with a general message space. Assume that each national regulatory agency (NRA) $i=1,2$ has committed to a message space $A_{i}$, and a regulatory policy $\left(q_{i}^{*}, t_{i}^{*}\right): A \rightarrow \mathbb{R}_{+} \times \mathbb{R}$, where $A=\left(A_{i}, A_{j}\right)$ (by the assumption of full transparency, the message space and regulatory polices are common knowledge $)$. Let $q^{*}=\left(q_{i}^{*}, q_{j}^{*}\right)$ and $t^{*}=\left(t_{i}^{*}, t_{j}^{*}\right)$. Let $a_{i}^{*}\left(\beta_{i}\right) \in A_{i}$ be the message chosen by national system operator (NSO) $i$ of type $\beta_{i} \in\{\underline{\beta}, \bar{\beta}\}$ under the regulatory policy $\left(q^{*}, t^{*}\right)$, and write $a^{*}(\beta)=\left(a_{i}^{*}\left(\beta_{i}\right), a_{j}^{*}\left(\beta_{j}\right)\right)$. In a dominant strategy Perfect Bayesian Equilibrium of the regulation game with general message space $A,\left(q^{*}, t^{*}\right)$ and $\left\{a^{*}(\beta)\right\}_{\beta \in\{\underline{\beta}, \bar{\beta}\}^{2}}$ satisfy for $i \neq j=1,2$, every $\beta \in\{\underline{\beta}, \bar{\beta}\}^{2}$ and for all $a_{i}, a_{j} \in A_{i} \times\left\{a_{j}^{*}(\underline{\beta}), a_{j}^{*}(\bar{\beta})\right\}$ :

$$
\begin{gathered}
t_{i}^{*}\left(a_{i}^{*}\left(\beta_{i}\right), a_{j}\right)-\psi\left(q_{i}^{*}\left(a_{i}^{*}\left(\beta_{i}\right), a_{j}\right) / \beta_{i}\right) \geq t_{i}^{*}\left(a_{i}, a_{j}\right)-\psi\left(q_{i}^{*}\left(a_{i}, a_{j}\right) / \beta_{i}\right) \\
t_{i}^{*}\left(a^{*}(\beta)\right)-\psi\left(q_{i}^{*}\left(a^{*}(\beta)\right) / \beta_{i}\right) \geq 0 .
\end{gathered}
$$

Condition (14) states that messages are required to be dominant strategies in regards to all messages reached by the opponent with positive probability, i.e. $a_{j}^{*}(\underline{\beta})$ and $a_{j}^{*}(\bar{\beta})$, but does not require dominance in regards to the entire message space $A_{j}$. Condition (15) states that participation should be profitable in equilibrium. Stronger strategy requirements, like dominance regarding the entire message space $A_{j}$, could be placed on the regulatory policies. These added restrictions would (weakly) limit the set of equilibrium policies. A further equilibrium requirement is that 
there exists no $\left(q_{i}, t_{i}\right)$ with corresponding messages $\{\widehat{a}(\beta)\}_{\beta \in\{\underline{\beta}, \bar{\beta}\}^{2}}$, where $\widehat{a}_{i}\left(\beta_{i}\right) \in A_{i}$ is the message chosen by $i$ of type $\beta_{i} \in\{\underline{\beta}, \bar{\beta}\}$ under the regulatory policy $\left(q_{i}, q_{j}^{*}, t_{i}, t_{j}^{*}\right)$, satisfying for $i \neq j=1,2$, every $\beta \in\{\underline{\beta}, \bar{\beta}\}^{2}$ and for all $a_{i}, a_{j} \in A_{i} \times\left\{\widehat{a}_{j}(\underline{\beta}), \widehat{a}_{j}(\bar{\beta})\right\}:$

$$
\begin{aligned}
& t_{i}\left(\widehat{a}_{i}\left(\beta_{i}\right), a_{j}\right)-\psi\left(q_{i}\left(\widehat{a}_{i}\left(\beta_{i}\right), a_{j}\right) / \beta_{i}\right) \geq t_{i}\left(a_{i}, a_{j}\right)-\psi\left(q_{i}\left(a_{i}, a_{j}\right) / \beta_{i}\right), \\
t_{i}(\widehat{a}(\beta))-\psi\left(q_{i}(\widehat{a}(\beta)) / \beta_{i}\right) \geq 0 & \\
W\left(q_{i}, q_{j}^{*}, t_{i}, t_{j}^{*}\right) & =\sum_{\beta \in\{\underline{\beta}, \bar{\beta}\}^{2}} \operatorname{Pr}(\beta)\left[P\left(q_{i}(\widehat{a}(\beta)), q_{j}^{*}(\widehat{a}(\beta)) \triangle S_{i}-\psi\left(q_{i}(\widehat{a}(\beta)) / \beta_{i}\right)-\lambda t_{i}(\widehat{a}(\beta))\right]\right. \\
> & \sum_{\beta \in\{\underline{\beta}, \bar{\beta}\}^{2}} \operatorname{Pr}(\beta)\left[P\left(q_{i}^{*}\left(a^{*}(\beta)\right), q_{j}^{*}\left(a^{*}(\beta)\right) \triangle S_{i}-\psi\left(q_{i}\left(a^{*}(\beta)\right) / \beta_{i}\right)-\lambda t_{i}\left(a^{*}(\beta)\right)\right]\right. \\
& =W\left(q^{*}, t^{*}\right),
\end{aligned}
$$

where $\operatorname{Pr}(\bar{\beta}, \bar{\beta})=v^{2}$, etc. Conditions (16)-(18) state that there should exist no strictly profitable dominant strategy implementable policy deviation $\left(q_{i}, t_{i}\right)$ for $i$. Conditions (14)-(18) jointly define a Perfect Bayesian Equilibrium (because out-of-equilibrium beliefs remain unspecified).

Consider instead an alternative game in which both regulators commit to offering DSID mechanisms. For $i=1,2$, let $q_{i}^{S}(\beta)=q_{i}^{*}\left(a^{*}(\beta)\right)$ and $t_{i}^{S}(\beta)=t_{i}^{*}\left(a^{*}(\beta)\right)$. It is easy to verify that (14) and (15) render truth-telling a (weakly) dominant strategy and participation profitable in the direct mechanism. To show that $\left(q^{S}, t^{S}\right)$ does constitute an equilibrium, I need to verify that $i$ cannot profitably deviate from $\left(q_{i}^{S}, t_{i}^{S}\right)$ to some other DSID policy $\left(\widetilde{q}_{i}, \widetilde{t}_{i}\right)$ given $\left(q_{j}^{S}, t_{j}^{S}\right)$. Suppose, on the contrary, that such a profitable deviation $\left(\widetilde{q}_{i}, \widetilde{t}_{i}\right)$ would exist. Return to the general message game, and define an alternative regulatory policy $\left(q_{i}, t_{i}\right)$ :

$$
\left(q_{i}(a), t_{i}(a)\right)=\left\{\begin{array}{cl}
\left(\widetilde{q}_{i}(\beta), \widetilde{t}_{i}(\beta)\right) & \text { if } a=a^{*}(\beta) \\
(h>0,0) & \text { for all } a \notin\left\{a_{i}^{*}(\underline{\beta}), a_{i}^{*}(\bar{\beta})\right\} \times A_{j}
\end{array}\right.
$$

Under the assumption that $j$ does not alter its message strategy with the introduction of the alternative strategy $\left(q_{i}, t_{i}\right)$, i.e. $\widehat{a}_{j}(\underline{\beta})=a_{j}^{*}(\underline{\beta})$ and $\widehat{a}_{j}(\bar{\beta})=a_{j}^{*}(\bar{\beta})$ holds, DSID of $\left(\widetilde{q}_{i}, \widetilde{t}_{i}\right)$ implies that an NSO $i$ of type $\beta_{i} \in\{\underline{\beta}, \bar{\beta}\}$ earns a non-negative profit by reporting $\widehat{a}_{i}\left(\beta_{i}\right)=a_{i}^{*}\left(\beta_{i}\right)$ and cannot benefit from deviating to $a_{i}^{*}\left(b_{i}\right)$, where $b_{i} \in\{\underline{\beta}, \bar{\beta}\}$ and $b_{i} \neq \beta_{i}$. Deviating to $a_{i} \notin\left\{a_{i}^{*}(\underline{\beta}), a_{i}^{*}(\bar{\beta})\right\}$ is strictly unprofitable because then $t_{i}(a)-\psi\left(q_{i}(a) / \beta_{i}\right)=-\psi\left(h / \beta_{i}\right)<0$. Given that $j$ does not modify its message strategy under the new policy, it is not profitable for $i$ to alter its message strategy either. Since the regulatory policy $\left(q_{j}^{*}, t_{j}^{*}\right)$ is the same as before, it is optimal for $j$ to maintain its message strategy $\widehat{a}_{j}\left(\beta_{j}\right)=a_{j}^{*}\left(\beta_{j}\right)$ for all $\beta_{j} \in\{\underline{\beta}, \bar{\beta}\}$ given that $i$ does not alter its message strategy under the new policy. Hence, unaltered message strategies 
are mutually optimal, and therefore $\left(q_{i}, t_{i}\right)$ satisfies (16) and (17). Moreover

$$
W_{i}\left(q_{i}, q_{j}^{*}, t_{i}, t_{j}^{*}\right)=W_{i}\left(\widetilde{q}_{i}, q_{j}^{S}, \widetilde{t}_{i}, t_{j}^{S}\right)>W_{i}\left(q^{S}, t^{S}\right)=W_{i}\left(q^{*}, t^{*}\right)
$$

where the equalities hold by construction of the regulatory policies $\left(\widetilde{q}_{i}, \widetilde{t}_{i}\right)$ and $\left(q^{S}, t^{S}\right)$, and the inequality follows from the assumption that a deviation to $\left(\widetilde{q}_{i}, \widetilde{t}_{i}\right)$ is strictly profitable. The existence of a profitable unilateral deviation contradicts the assumption that $\left(q^{*}, t^{*}\right)$ is an equilibrium. Hence, if $\left(q^{*}, t^{*}\right)$ is indeed an equilibrium, then there cannot exist any profitable unilateral DSID deviation $\left(\widetilde{q}_{i}, \widetilde{t}_{i}\right)$ from $\left(q_{i}^{S}, t_{i}^{S}\right)$ and therefore $\left(q^{S}, t^{S}\right)$ constitutes an equilibrium. The equilibrium policies and welfare are the same in both games, hence they are equivalent.

\section{Proof of Lemma 3}

Consider the unconstrained maximization of $\Gamma^{C r}(\mathbf{q})$. I verify ex post that the (unique) solution satisfies $\mathbf{q}^{C r}>\mathbf{0}, \bar{q}^{C r}>\widetilde{q}^{C r}$ and $\widehat{q}^{C r}>\underline{q}^{C r}$. By the boundary condition (BC), all maxima of $\Gamma^{C r}$ by necessity are contained in $[0, k]^{4}$. Maximization of a continuous function on a compact set yields an optimum. Concavity of $P$, strict convexity of $\psi$ and convexity of $\Phi$ render $\Gamma^{C r}$ strictly concave, hence the optimum is unique and given by $\mathbf{q}^{C r}$, characterized in (8). The solution is interior $\left(\mathbf{q}^{C r}>\mathbf{0}\right)$ by the assumption that $P_{1}^{\prime}\left(0, q_{2}\right)>0$ for all $q_{2} \geq 0$ and $\psi^{\prime}(0)=\Phi^{\prime}(0)=0$. Now to the monotonicity constraints.

Quality complementarity implies $\bar{q}^{C r}>\widehat{q}^{C r}>\widetilde{q}^{C r}>\underline{q}^{C r}$ : Recall the generalized virtual maintenance cost (13) and define implicitly $q^{C r}(\beta)$ by $2 P_{i}^{\prime}\left(q^{C r}\right)\left(\mu_{1} \triangle S_{1}+\mu_{2} \triangle S_{2}\right)=c_{i}^{\prime}\left(q_{i}^{C r} ; \beta_{i}\right)$, $i=1,2$. Now, $\bar{q}^{C r}-\widehat{q}^{C r}=\int_{\underline{\beta}}^{\bar{\beta}}\left(\partial q_{i}^{C r}\left(\bar{\beta}, \beta_{j}\right) / \partial \beta_{j}\right) d \beta_{j}$. Since

$\frac{\partial q_{i}^{C r}(\beta)}{\partial \beta_{j}}=\frac{2 P_{i j}^{\prime \prime}\left(\mu_{1} \triangle S_{1}+\mu_{2} \triangle S_{2}\right)(1+\lambda)\left(1+\frac{v}{1-v} \frac{\lambda}{1+\lambda}\right) \Phi^{\prime}\left(q_{j}^{C r}\right) /(\bar{\beta}-\underline{\beta})}{4\left(P_{11}^{\prime \prime} P_{22}^{\prime \prime}-P_{12}^{\prime \prime} P_{21}^{\prime \prime}\right)\left(\mu_{1} \triangle S_{1}+\mu_{2} \triangle S_{2}\right)^{2}-2\left(P_{11}^{\prime \prime} c_{22}^{\prime \prime}+P_{22}^{\prime \prime} c_{11}^{\prime \prime}\right)\left(\mu_{1} \triangle S_{1}+\mu_{2} \triangle S_{2}\right)+c_{11}^{\prime \prime} c_{22}^{\prime \prime}}$,

$\bar{q}^{C r}>\widehat{q}^{C r}$ if $P_{i j}^{\prime \prime}>0$. Similarly, $\widetilde{q}^{C r}-\underline{q}^{C r}=\int_{\underline{\beta}}^{\bar{\beta}}\left(\partial q_{i}^{C r}\left(\underline{\beta}, \beta_{j}\right) / \partial \beta_{j}\right) d \beta_{j}$ implies $\widetilde{q}^{C r}>\underline{q}^{C r}$ if $P_{i j}^{\prime \prime}>0$. I complete the quality complementarity case by showing that $\widehat{q}^{C r}>\widetilde{q}^{C r}$ if $P_{i j}^{\prime \prime}>0$. Suppose on the contrary that $P_{i j}^{\prime \prime}>0$ and $\widetilde{q}^{C r} \geq \widehat{q}^{C r}$. Convexity of $\psi$ and $\Phi$ then imply $P_{1}^{\prime}\left(\widetilde{q}^{C r}, \widehat{q}^{C r}\right)>P_{1}^{\prime}\left(\widehat{q}^{C r}, \widetilde{q}^{C r}\right)$; see (8). By $P_{11}^{\prime \prime}<0, \widetilde{q}^{C r} \geq \widehat{q}^{C r}$ implies $P_{1}^{\prime}\left(\widehat{q}^{C r}, \widetilde{q}^{C r}\right) \geq P_{1}^{\prime}\left(\widetilde{q}^{C r}, \widetilde{q}^{C r}\right)$. Complementarity and $\widetilde{q}^{C r} \geq \widehat{q}^{C r}$ imply $P_{1}^{\prime}\left(\widetilde{q}^{C r}, \widetilde{q}^{C r}\right) \geq P_{1}^{\prime}\left(\widetilde{q}^{C r}, \widehat{q}^{C r}\right)$. Combining these inequalities I arrive at a contradiction: $P_{1}^{\prime}\left(\widetilde{q}^{C r}, \widehat{q}^{C r}\right)>P_{1}^{\prime}\left(\widehat{q}^{C r}, \widetilde{q}^{C r}\right) \geq P_{1}^{\prime}\left(\widetilde{q}^{C r}, \widetilde{q}^{C r}\right) \geq P_{1}^{\prime}\left(\widetilde{q}^{C r}, \widehat{q}^{C r}\right)$. Thus, quality complementarity implies $\widehat{q}^{C r}>\widetilde{q}^{C r}$.

Quality substitutability implies $\widehat{q}^{C r}>\bar{q}^{C r}>\underline{q}^{C r}>\widetilde{q}^{C r}$ : If $P_{i j}^{\prime \prime}<0$, then $\partial q_{i}^{C r}(\beta) / \partial \beta_{j}<0$ and therefore $\widehat{q}^{C r}>\bar{q}^{C r}$ and $\underline{q}^{C r}>\widetilde{q}^{C r}$, see above. Finally, $P_{i j}^{\prime \prime}<0$ implies $\bar{q}^{C r}>\underline{q}^{C r}$. Subtract 
the foc for $\bar{q}^{C r}$ from the foc for $\underline{q}^{C r}$ in (8) and rearrange:

$$
\begin{aligned}
& 2\left(P_{1}^{\prime}\left(\underline{q}^{C r}, \underline{q}^{C r}\right)-P_{1}^{\prime}\left(\bar{q}^{C r}, \bar{q}^{C r}\right)\right)\left(\mu_{1} \triangle S_{1}+\mu_{2} \triangle S_{2}\right) \\
= & (1+\lambda)\left(\psi^{\prime}\left(\underline{q}^{C r} / \bar{\beta}\right) / \bar{\beta}-\psi^{\prime}\left(\bar{q}^{C r} / \bar{\beta}\right) / \bar{\beta}\right)+(1+\lambda)\left(1+\frac{v}{1-v} \frac{\lambda}{1+\lambda}\right) \Phi^{\prime}\left(\underline{q}^{C r}\right) .
\end{aligned}
$$

For $\underline{q}^{C r} \geq \bar{q}^{C r}$, the right-hand side of the above expression is strictly positive because $\psi^{\prime \prime}>0$ and $\Phi^{\prime}>0$ for all $\underline{q}^{C r}>0$. Under quality substitutability, $\underline{q}^{C r} \geq \bar{q}^{C r}$ implies that the left-hand side is non-positive because $d P_{1}^{\prime}\left(q_{1}, q_{1}\right)=\left(P_{11}^{\prime \prime}\left(q_{1}, q_{1}\right)+P_{12}^{\prime \prime}\left(q_{1}, q_{1}\right)\right) d q_{1}<0$ - a contradiction. Thus, $P_{i j}^{\prime \prime}<0$ implies $\bar{q}^{C r}>\underline{q}^{C r}$.

The final part is to show the effect on network quality of increasing $\mu_{i}$. By straightforward differentiation of $q^{C r}(\beta)$ :

$\frac{d q_{1}^{C r}}{d \mu_{i}}=\frac{2\left(P_{1}^{\prime} c_{22}^{\prime \prime}+2\left(P_{2}^{\prime} P_{12}^{\prime \prime}-P_{1}^{\prime} P_{22}^{\prime \prime}\right)\left(\mu_{1} \triangle S_{1}+\mu_{2} \triangle S_{2}\right)\right)\left(\triangle S_{i}-\triangle S_{j}\right)}{4\left(P_{11}^{\prime \prime} P_{22}^{\prime \prime}-P_{12}^{\prime \prime} P_{21}^{\prime \prime}\right)\left(\mu_{1} \triangle S_{1}+\mu_{2} \triangle S_{2}\right)^{2}-2\left(P_{11}^{\prime \prime} c_{22}^{\prime \prime}+P_{22}^{\prime \prime} c_{11}^{\prime \prime}\right)\left(\mu_{1} \triangle S_{1}+\mu_{2} \triangle S_{2}\right)+c_{11}^{\prime \prime} c_{22}^{\prime \prime}}$,

which is strictly positive if $\triangle S_{i}>\triangle S_{j}$ and condition (NG) holds. A similar expression holds for $d q_{2}^{C r} / d \mu_{i}>0$.

\section{Proof of Lemma 4}

Construct the Lagrangian

$$
L^{I}(\mathbf{q}, \bar{u})=\Gamma^{I}(\mathbf{q}, \bar{u})+\widetilde{\xi}(2 \bar{u}-\Phi(\underline{q})-\Phi(\widetilde{q}))+2 \underline{\xi}(\bar{u}-\Phi(\underline{q})),
$$

where $\widetilde{\xi}$ and $\underline{\xi}$ are the Kuhn-Tucker multipliers associated with $2 \bar{u}^{I} \geq \Phi(\underline{q})+\Phi(\widetilde{q})$ and $2 \bar{u}^{I} \geq$ $2 \Phi(\underline{q})$. Ignore for the moment the monotonicity constraint $\min \{\bar{q} ; \widehat{q}\} \geq \max \{\widetilde{q} ; \underline{q}\}$ and the nonnegativity constraint $\mathbf{q} \geq 0$. Concavity of $\Gamma^{I}(\mathbf{q}, \bar{u})$ and of both constraints imply concavity of $L^{I}(\mathbf{q}, \bar{u})$. Hence, the first-order conditions and complementary slackness conditions characterized in (11) are necessary and sufficient for optimality of $L^{I}(\mathbf{q}, \bar{u})$. By the boundary condition (BC), every solution to the problem of maximizing $\Gamma^{I}(\mathbf{q},(\Phi(\underline{q})+\max \{\Phi(\widetilde{q}) ; \Phi(\underline{q})\}) / 2)$ is contained in $[0, k]^{4}$. Maximization of a continuous function over a compact (and convex) domain yields an optimum. The solution is interior $\left(\mathbf{q}^{I}>0\right)$ by the assumptions that $P_{1}^{\prime}\left(0, q_{2}\right)>0$ for all $q_{2} \geq 0$ and $\psi^{\prime}(0)=\Phi^{\prime}(0)=0$. To complete the existence proof, I verify the monotonicity constraint $\min \left\{\bar{q}^{I} ; \widehat{q}^{I}\right\} \geq \max \left\{\widetilde{q}^{I} ; \underline{q}^{I}\right\}$.

Quality complementarity implies $\bar{q}^{I}>\widehat{q}^{I}>\widetilde{q}^{I}>\underline{q}^{I}$ : Assume that $\widetilde{q}^{I}>\underline{q}^{I}$. Then, $2 \bar{u}^{I} \geq$ 
$\Phi\left(\underline{q}^{I}\right)+\Phi\left(\widetilde{q}^{I}\right)>2 \Phi\left(\underline{q}^{I}\right)$ and so $\underline{\xi}^{I}=0$. Since $\widetilde{\xi}^{I}+\underline{\xi}^{I}=\lambda v^{2} / 2$, then $\widetilde{\xi}^{I}=\lambda v^{2} / 2$. Define $z^{I}(\theta)$ by

$$
2 P_{i}^{\prime}\left(z^{I}\right)\left(\mu_{1} \triangle S_{1}+\mu_{2} \triangle S_{2}\right)=(1+\lambda) \psi^{\prime}\left(z_{i}^{I} / \underline{\beta}\right) / \underline{\beta}+\frac{\lambda v}{2(1-v)}\left(1+\frac{1-\theta}{1-v}\right) \Phi^{\prime}\left(z_{i}^{I}\right)
$$

$2 P_{j}^{\prime}\left(z^{I}\right)\left(\mu_{1} \triangle S_{1}+\mu_{2} \triangle S_{2}\right)=(1+\lambda) \psi^{\prime}\left(z_{j}^{I} / \bar{\beta}\right) / \bar{\beta}+(1-\theta)\left(1+\lambda+\frac{\lambda v}{2(1-v)}\left(1+\frac{1-\theta}{1-v}\right)\right) \Phi^{\prime}\left(z_{j}^{I}\right)$

Plugging $\underline{\xi}^{I}=0$ and $\widetilde{\xi}^{I}=\lambda v^{2}$ into (11), it follows that $z_{i}^{I}(1)=\widetilde{q}^{I}, z_{j}^{I}(1)=\widehat{q}^{I}$ and $z_{i}^{I}(0)=$ $z_{j}^{I}(0)=\underline{q}^{I}$. Straightforward differentiation of $z^{I}(\theta)$ yields $d z_{i}^{I} / d \theta>0$ and $d z_{j}^{I} / d \theta>0$ if $P_{i j}^{\prime \prime}>0$. So for $P_{i j}^{\prime \prime}>0, \widetilde{q}^{I}>\underline{q}^{I}$ is indeed consistent. The proofs that $\bar{q}^{I}>\widehat{q}^{I}$ and $\widehat{q}^{I}>\widetilde{q}^{I}$ under quality complementarity are analogous the proofs in Lemma 3 that $P_{i j}^{\prime \prime}>0$ implies $\bar{q}^{C r}>\widehat{q}^{C r}$ and $\widehat{q}^{C r}>\widetilde{q}^{C r}$ and are thus omitted.

Quality substitutability implies $\widehat{q}^{I}>\bar{q}^{I}>\max \left\{\widetilde{q}^{I}, \underline{q}^{I}\right\}$ : The proofs that $\widehat{q}^{I}>\bar{q}^{I}$ and $\bar{q}^{I}>\underline{q}^{I}$ under quality substitutability are analogous to the proofs in Lemma 3 that $P_{i j}^{\prime \prime}<0$ implies $\widehat{q}^{C r}>$ $\bar{q}^{C r}$ and $\bar{q}^{C r}>\underline{q}^{C r}$ and are thus omitted. The proof that $\bar{q}^{I}>\widetilde{q}^{I}$ under quality substitutability is analogous the proof in Lemma 2 that $\bar{q}_{i}^{S}>\widetilde{q}_{i}^{S}$ and is also omitted.

The final part is to compare quality levels under Integration with quality levels under Common regulation. Moving from Common regulation to Integration is qualitatively the same as lowering the virtual marginal maintenance cost of the least productive network when the two networks differ in productivity. The difference is $\left(\lambda v^{2}+2 \underline{\xi}^{I}\right) \Phi^{\prime}(\widetilde{q}) / 2 v(1-v)>0$. Under quality complementarity, lower marginal cost in one part of the network translates into higher maintenance spending in the entire network. Thus, $\widehat{q}^{I}>\widehat{q}^{C r}$ and $\widetilde{q}^{I}>\widetilde{q}^{C r}$ in this case. A switch from Common regulation to Integration is qualitatively the same as raising the virtual marginal cost of both networks by the same factor when the two networks have the same low productivity. The difference is $\left(\lambda v^{2}+2 \underline{\xi}^{I}\right) \Phi^{\prime}(\underline{q}) / 2(1-v)^{2}>0$. Under quality complementarity, higher marginal costs in both parts of the network translate into lower maintenance spending in the entire network. Thus, $\underline{q}^{I}<\underline{q}^{C r}$ in this case.

Under quality substitutability, $P_{1}^{\prime}\left(q_{1}, q_{1}\right)$ is strictly decreasing in $q_{1}$. Thus, $\underline{q}^{I} \geq \underline{q}^{C r}$ would imply $P_{1}^{\prime}\left(\underline{q}^{I}, \underline{q}^{I}\right) \leq P_{1}^{\prime}\left(\underline{q}^{C r}, \underline{q}^{C r}\right)$. Convexity and the difference in virtual marginal maintenance would yield $P_{1}^{\prime}\left(\underline{q}^{I}, \underline{q}^{I}\right)>P_{1}^{\prime}\left(\underline{q}^{C r}, \underline{q}^{C r}\right)$ for $\underline{q}^{I} \geq \underline{q}^{C r}$, see the first-order conditions. This is a contradiction. Thus, $\underline{q}^{I}<\underline{q}^{C r}$ even under quality substitutability. The case when the two networks differ in productivity is more complicated. Again, $\widetilde{q}^{I}>\widetilde{q}^{C r}$ owing to a lower marginal cost under Integration. However, $\widehat{q}^{I}<\widehat{q}^{C r}$ due to quality substitutability. The overall effect on network reliability is ambiguous, but under condition (NG), the direct effect dominates and so 
$P\left(\widehat{q}^{I}, \widetilde{q}^{I}\right)>P\left(\widehat{q}^{C r}, \widetilde{q}^{C r}\right)$; see the proof on Lemma 5 for an example of this type of result.

\section{Proof of Proposition 1}

Recall the definition of the generalized virtual maintenance cost $c\left(q_{i} ; \beta_{i}\right)$ in (13). In the case of two national system operators, welfare is proportional to

$$
w(q)=P(q)\left(\triangle S_{1}+\triangle S_{2}\right)-c\left(q_{1} ; \beta_{1}\right)-c\left(q_{2} ; \beta_{2}\right)
$$

whenever the distribution of productivity is $\beta=\left(\beta_{1}, \beta_{2}\right)$. At $\beta$, the welfare difference between Common regulation and Separation is proportional to $w\left(q^{C r}\left(\beta, \mu_{i}\right)\right)-w\left(q^{S}(\beta)\right)$. Assume without loss of generality that $\triangle S_{i}>\triangle S_{j}$, and differentiate:

$$
\begin{aligned}
\frac{d w\left(q^{C r}\left(\beta, \mu_{i}\right)\right)}{d \mu_{i}} & =\left(P_{1}^{\prime}\left(q^{C r}\right)\left(\triangle S_{1}+\triangle S_{2}\right)-c_{1}^{\prime}\left(q_{1}^{C r} ; \beta_{1}\right)\right) \frac{d q_{1}^{C r}}{d \mu_{i}}+\left(P_{2}^{\prime}\left(q^{C r}\right)\left(\triangle S_{1}+\triangle S_{2}\right)-c_{2}^{\prime}\left(q_{2}^{C r} ; \alpha_{2}\right)\right) \frac{d q_{2}^{C r}}{d \mu_{i}} \\
& =\left(1-2 \mu_{i}\right)\left(\triangle S_{i}-\triangle S_{j}\right)\left(P_{1}^{\prime}\left(q^{C r}\right) \frac{d q_{1}^{C r}}{d \mu_{i}}+P_{2}^{\prime}\left(q^{C r}\right) \frac{d q_{2}^{C r}}{d \mu_{i}}\right),
\end{aligned}
$$

where I have substituted in the first-order condition $c_{i}^{\prime}\left(q_{i}^{C r} ; \beta_{i}\right)=2 P_{i}^{\prime}\left(q^{C r}\right)\left(\mu_{1} \triangle S_{1}+\mu_{2} \triangle S_{2}\right)$ (see the proof of Lemma 3 ) and simplified. If condition (NG) holds (quality is a normal good), then $d q_{1}^{C r} / d \mu_{i}>0$ and $d q_{2}^{C r} / d \mu_{i}>0$ (Lemma 3) and so $w\left(q^{C r}\left(\beta, \mu_{i}\right)\right)-w\left(q^{S}(\beta)\right)$ is single-peaked in $\mu_{i}$ with a unique optimum at $\mu_{i}=1 / 2$. Clearly, $w(q)$ reaches its maximum at $q^{C r}(\beta, 1 / 2)$ (because the first-order conditions under Common regulation then are identical to the ones under welfare maximization and the optimum is unique). Thus, $w\left(q^{C r}(\beta, 1 / 2)\right)>w\left(z^{S}(\beta)\right)$, which together with single-peakedness proves the existence of $\underline{\mu} \in[0,1 / 2)$ and $\bar{\mu} \in(1 / 2,1]$ such that for all $\beta: w\left(q^{C r}\left(\beta, \mu_{i}\right)\right) \geq w\left(q^{S}(\beta)\right)$ if and only if $\mu_{i} \in[\mu, \bar{\mu}]$ - with strict inequality in the interior.

I complete the proof by showing that Separation welfare dominates Common regulation and Integration for $\mu_{2}=1$ and all $\triangle S_{2}$ low, but positive. For $\mu_{2}=1, \mathbf{q}^{C r} \rightarrow \mathbf{0}$ and $\mathbf{q}^{I} \rightarrow \mathbf{0}$ as $\triangle S_{2} \rightarrow 0$ because the perceived gains from market integration then vanish. Thus, $\sum_{i=1,2} W_{i}\left(\mathbf{q}^{C r}, \mathbf{q}^{C r}, \mathbf{u}^{C r}\right) \rightarrow P(0,0) \triangle S_{1}$ and $\sum_{i=1,2} W_{i}\left(\mathbf{q}^{I}, \mathbf{q}^{I}, \mathbf{u}^{I}\right) \rightarrow P(0,0) \triangle S_{1}$ as $\triangle S_{2} \rightarrow 0$. Under Separation, $\mathbf{q}_{2}^{S} \rightarrow 0$ as $\triangle S_{2} \rightarrow 0$, but $\mathbf{q}_{1}^{S} \rightarrow \mathbf{q}_{10}^{S}=\left(\bar{q}_{10}^{S}, \bar{q}_{10}^{S}, \underline{q}_{10}^{S}, \underline{q}_{10}^{S}\right)>\mathbf{0}$ as $\triangle S_{2} \rightarrow 0$, where $P_{1}^{\prime}\left(\bar{q}_{10}^{S}, 0\right) \triangle S_{1}=c_{1}^{\prime}\left(\bar{q}_{10}^{S} ; \bar{\beta}\right)$ and $P_{1}^{\prime}\left(\underline{q}_{10}^{S}, 0\right) \triangle S_{1}=c_{1}^{\prime}\left(\underline{q}_{10}^{S} ; \underline{\beta}\right)$. The policy $\mathbf{q}_{10}^{S}$ is also the welfare maximizing choice of $\mathbf{q}_{1}$ conditional on $\triangle S_{2}=0$ and $\mathbf{q}_{2}=0$. Thus, $\sum_{i=1,2} W_{i}\left(\mathbf{Q}^{S}, \mathbf{u}_{i}^{S}\right) \rightarrow$ $W_{1}\left(\left(\mathbf{q}_{10}^{S}, \mathbf{0}\right), \mathbf{u}_{10}^{S}\right)+W_{2}\left(\left(\mathbf{q}_{10}^{S}, \mathbf{0}\right), \mathbf{0}\right)>P(0,0) \triangle S_{1}$ as $\triangle S_{2} \rightarrow 0$. By continuity, Separation welfare dominates Common regulation and Integration for $\mu_{2}=0$ and all $\triangle S_{2}$ low, but positive.

\section{Proof of Proposition 2}


Quality complementarity implies $\bar{q}^{C r}>\widehat{q}^{C r}>\widetilde{q}^{C r}>\underline{q}^{C r}$, see the proof of Lemma 3. The monotonicity constraint $\min \left\{\bar{q}^{C r}, \widehat{q}^{C r}\right\} \geq \max \left\{\widetilde{q}^{C r} ; \underline{q}^{C r}\right\}$ is satisfied and so the CRA can implement $\mathbf{q}^{C r}$ under a CSO by means of the transfers $2 \bar{t}=2 \psi\left(\bar{q}^{C r} / \bar{\beta}\right)+\Phi\left(\underline{q}^{C r}\right)+\Phi\left(\widetilde{q}^{C r}\right)$, $\widehat{t}+\widetilde{t}=\psi\left(\widehat{q}^{C r} / \bar{\beta}\right)+\psi\left(\widetilde{q}^{C r} / \underline{\beta}\right)+\Phi\left(\underline{q}^{C r}\right)$ and $2 \underline{t}=2 \psi\left(\underline{q}^{C r} / \underline{\beta}\right)$. I omit the proof, which simply amounts to verifying that the CSO's incentive and participation constraints are all met by this contract. Weighted welfare equals

$$
\begin{aligned}
\Gamma^{I}\left(\mathbf{q}^{I}, \bar{u}^{I}\right) & >\Gamma^{I}\left(\mathbf{q}^{C r},\left(\Phi\left(\underline{q}^{C r}\right)+\Phi\left(\widetilde{q}^{C r}\right)\right) / 2\right) \\
& =\Gamma^{C r}\left(\mathbf{q}^{C r}\right)+\lambda v^{2}\left(\Phi\left(\widetilde{q}^{C r}\right)-\Phi\left(\underline{q}^{C r}\right)\right) / 2 \\
& >\Gamma^{C r}\left(\mathbf{q}^{C r}\right)
\end{aligned}
$$

The first inequality follows from uniqueness of $\mathbf{q}^{I} \neq \mathbf{q}^{C r}$ under Integration. The second inequality follows from $\widetilde{q}^{C r}>\underline{q}^{C r}$ under quality complementarity and $\Phi^{\prime}>0$ for all $q_{i}>0$. Since $\mathbf{q}^{I}$ $\left[\mathbf{q}^{C r}\right]$ is the socially optimal regulatory policy when there is a CSO [two NSOs] for $\mu_{1}=1 / 2$, Integration welfare dominates Common regulation for $\mu_{1} \approx 1 / 2$ in this case. Quality complementarity implies that $(\mathrm{NG})$ is satisfied and therefore Common regulation welfare dominates Separation for $\mu_{1} \approx 1 / 2$; see Proposition 1 .

\section{Proof of Proposition 3}

Quality substitutability implies $\widehat{q}^{I}>\bar{q}^{I}>\max \left\{\widetilde{q}^{I}, \underline{q}^{I}\right\}$, see the proof of Lemma 4. Both monotonicity constraints $\bar{q}^{I} \geq \widetilde{q}^{I}$ and $\widehat{q}^{I} \geq \underline{q}^{I}$ are met, so the CRA can implement $\mathbf{q}^{I}$ in dominating strategies under Common regulation by means of the transfers $\bar{t}=\psi\left(\bar{q}^{I} / \bar{\beta}\right)+\Phi\left(\widetilde{q}^{I}\right)$, $\widehat{t}=\psi\left(\widehat{q}^{I} / \bar{\beta}\right)+\Phi\left(\underline{q}^{I}\right), \widetilde{t}=\psi\left(\widetilde{q}^{I} / \underline{\beta}\right)$ and $\underline{t}=\psi\left(\underline{q}^{I} / \underline{\beta}\right)$. Weighted welfare equals

$$
\begin{aligned}
\Gamma^{C r}\left(\mathbf{q}^{C r}\right) & >\Gamma^{C r}\left(\mathbf{q}^{I}\right) \\
& =\Gamma^{I}\left(\mathbf{q}^{I}, \bar{u}^{I}\right)+\lambda v^{2}\left(\Phi\left(\underline{q}^{I}\right)+\max \left\{\Phi\left(\widetilde{q}^{I}\right) ; \Phi\left(\underline{q}^{I}\right)\right\}-2 \Phi\left(\widetilde{q}^{I}\right)\right) / 2 \\
& \gtreqless \Gamma^{I}\left(\mathbf{q}^{I}, \bar{u}^{I}\right) .
\end{aligned}
$$

The first inequality follows from uniqueness of $\mathbf{q}^{C r} \neq \mathbf{q}^{I}$ under Common regulation. The last inequality is non-negative if $\underline{q}^{I} \geq \widetilde{q}^{I}$, in which case Common regulation is strictly better than Integration. It is negative if $\underline{q}^{I}<\widetilde{q}^{I}$, and the welfare difference between Integration and Common regulation then is ambiguous. I now show how the sign of $\underline{q}^{I}-\widetilde{q}^{I}$ depends on the social cost $\lambda v$ of informational rent.

If the social cost $\lambda v$ of informational rent is low, then $\underline{q}^{I} \geq \widetilde{q}^{I}$. To prove this claim I only have to verify that $\underline{q}^{I}>\widetilde{q}^{I}$ is indeed consistent for low $\lambda v$ because the first-order conditions are 
necessary and sufficient. If $\underline{q}^{I}>\widetilde{q}^{I}$, then $2 \bar{u}^{I} \geq 2 \Phi\left(\underline{q}^{I}\right)>\Phi\left(\underline{q}^{I}\right)+\Phi\left(\widetilde{q}^{I}\right)$ and by implication $\widetilde{\xi}^{I}=0$ and $\underline{\xi}^{I}=\lambda v^{2} / 2$. Plugging these Kuhn-Tucker multipliers into (11), yields

$$
\begin{aligned}
& 2 P_{1}^{\prime}\left(\bar{q}^{I}, \bar{q}^{I}\right)\left(\mu_{1} \triangle S_{1}+\mu_{2} \triangle S_{2}\right)=(1+\lambda) \psi^{\prime}\left(\bar{q}^{I} / \bar{\beta}\right) / \bar{\beta} \\
& 2 P_{1}^{\prime}\left(\widehat{q}^{I}, \widetilde{q}^{I}\right)\left(\mu_{1} \triangle S_{1}+\mu_{2} \triangle S_{2}\right)=(1+\lambda) \psi^{\prime}\left(\widehat{q}^{I} / \bar{\beta}\right) / \bar{\beta} \\
& 2 P_{1}^{\prime}\left(\widetilde{q}^{I}, \widehat{q}^{I}\right)\left(\mu_{1} \triangle S_{1}+\mu_{2} \triangle S_{2}\right)=(1+\lambda) \psi^{\prime}\left(\widetilde{q}^{I} / \underline{\beta}\right) / \underline{\beta} \\
& 2 P_{1}^{\prime}\left(\underline{q}^{I}, \underline{q}^{I}\right)\left(\mu_{1} \triangle S_{1}+\mu_{2} \triangle S_{2}\right)=(1+\lambda)\left(\psi^{\prime}\left(\underline{q}^{I} / \underline{\beta}\right) / \underline{\beta}+\frac{\lambda}{1+\lambda} \frac{v}{(1-v)^{2}} \Phi^{\prime}\left(\underline{q}^{I}\right)\right) .
\end{aligned}
$$

For $\lambda v=0$, it is easy to verify that $\underline{q}^{I}>\widetilde{q}^{I}$ by applying the same procedure used to prove $\underline{q}^{f b}>\widetilde{q}^{f b}$ under substitutability in the proof of Lemma 2. By continuity, $\underline{q}^{I}>\widetilde{q}^{I}$ extends even to $\lambda v>0$, if $\lambda v$ is not too large.

If the social cost $\lambda v$ of informational rent is large, then $\underline{q}^{I}<\widetilde{q}^{I}$. For all large $\lambda v, \widetilde{q}^{I} \leq \underline{q}^{I}$ would imply

$$
\frac{P_{1}^{\prime}\left(\widetilde{q}^{I}, \widehat{q}^{I}\right)}{P_{1}^{\prime}\left(\underline{q}^{I}, \underline{q}^{I}\right)}>\frac{1}{1+\frac{\lambda}{1+\lambda} \frac{v}{(1-v)^{2}}\left(1-\frac{\beta}{\bar{\beta}} \frac{\psi^{\prime}\left(\widetilde{q}^{I} / \bar{\beta}\right)}{\psi^{\prime}\left(\widetilde{q}^{I} / \underline{\beta}\right)}\right)} \geq \frac{\psi^{\prime}\left(\widetilde{q}^{I} / \underline{\beta}\right) / \underline{\beta}}{\psi^{\prime}\left(\underline{q}^{I} / \underline{\beta}\right) / \underline{\beta}+\frac{\lambda}{1+\lambda} \frac{v}{(1-v)^{2}} \Phi^{\prime}\left(\underline{q}^{I}\right)}=\frac{P_{1}^{\prime}\left(\widetilde{q}^{I}, \widehat{q}^{I}\right)}{P_{1}^{\prime}\left(\underline{q}^{I}, \underline{q}^{I}\right)}
$$

which is a contradiction. To understand the first, strict inequality note that $P_{1}^{\prime}\left(\widetilde{q}^{I}, \widehat{q}^{I}\right) / P_{1}^{\prime}\left(\underline{q}^{I}, \underline{q}^{I}\right)$ is bounded away from zero because $\left(\widetilde{q}^{I}, \widehat{q}^{I}\right) \in[0, k]^{2}, \underline{q}^{I} \in[0, k]$ and $P_{i}^{\prime}$ is well defined for all $q \geq 0$. Secondly, $\psi^{\prime}\left(q_{i} / \bar{\beta}\right)<\psi^{\prime}\left(q_{i} / \underline{\beta}\right)$ for all $q_{i}>0$ and therefore $\lim _{q_{i} \rightarrow 0} \psi^{\prime}\left(q_{i} / \bar{\beta}\right) / \psi^{\prime}\left(q_{i} / \underline{\beta}\right) \leq 1$ by continuity. Thus, the second term goes to zero as $\lambda v \rightarrow \infty$. The second, weak inequality follows from the assumption that $\widetilde{q}^{I} \leq \underline{q}^{I}$, and the equality follows from the focs above.

The argument why Common regulation welfare dominates Integration and Separation if network quality is also a normal good and political influence of the two countries is balanced $\left(\mu_{1} \approx 1 / 2\right)$ is the same as why Integration welfare dominates Common regulation and Separation under quality complementarity; see the proof of Proposition 2.

\section{References}

Armstrong, M., and D.E.M. Sappington (2007): "Recent Developments in the Theory of Regulation", in M. Armstrong and R. Porter (eds.): Handbook of Industrial Organization (vol. 3), Amsterdam: North-Holland, 1557-1700.

Attar, A., E. Campioni and G. Piaser (2010): "Information Revelation in Competing Mechanism Games", manuscript, IDEI.

Auriol, E. and S. Biancini (2009): "Economic Integration and Investment Incentives in Regu- 
lated Industries", IDEI WP 555.

Brainard, S.L. and D. Martimort (1996): "Strategic Trade Policy Design with Asymmetric Information and Public Contracts", Review of Economic Studies 63, 81-105.

Combes, P.-P., B. Caillaud and B. Jullien (1997): "Common Market with Regulated Firms", Annales d'Économie et de Statistique 47, 65-98.

Cremer, H., J. Cremér and P. De Donder (2006): "Legal vs. Ownership Unbundling in Network Industries", IDEI WP 405.

Dana, J.D. (1993): "The Organization and Scope of Agents: Regulating Multiproduct Industries", Journal of Economic Theory 59, 288-310.

Ellingsen, T. (1998): "Externalities vs. Internalities: A Model of Political Integration", Journal of Public Economics 68, 251-268.

EMG (2008): "One Nordic System Operator: Investigating if and how a Nordic System Operator may be Established", Nordic Council of Ministers Electricity Market Group.

EU (2009a): "Regulation (EC) No 713/2009 of the European Parliament and of the Council of 13 July 2009 establishing an Agency for the Cooperation of Energy Regulators", Official Journal of the European Union, 14.8.2009.

EU (2009b): "Directive 2009/72/EC of the European Parliament and of the Council of 13 July 2009 concerning common rules for the internal market in electricity and repealing Directive 2003/54/EC", Official Journal of the European Union, 14.8.2009.

European Commission (2007): "An Energy Policy for Europe", COM(2007)1 final.

Kolstad, C.D. and L. Mathiesen (1987): "Necessary and Sufficient Conditions for Uniqueness of a Cournot Equilibrium", Review of Economic Studies LIV, 681-690.

Laffont, J.-J. and J. Pouyet (2003): "The Subsidiarity Bias in Regulation", Journal of Public Economics 88, 255-283.

Laffont, J.-J. and J. Tirole (1993): A Theory of Incentives in Procurement and Regulation, Cambridge, Mass: MIT Press. 
Martimort, D. (2007): "Multi-Contracting Mechanism Design", in R. Blundell, W.K. Newey and T. Persson (eds.): Advances in Economics and Econometrics, Cambridge: Cambridge University Press, 57-101.

Mookherjee, D. and S. Reichelstein (1992): "Dominant Strategy Implementation of Bayesian Incentive Compatible Allocation Rules", Journal of Economic Theory 56, 378-399.

Oates, W. (1972): Fiscal Federalism, New York: Harcourt-Brace.

Olsen, T.E. and G. Torsvik (1993): "The Ratchet Effect in Common Agency: Implications for Regulation and Privatization", Journal of Law, Economics, $\&$ Organization 9, 136-158.

Pollitt, M. (2008): "The Arguments For and Against Ownership Unbundling of Energy Transmission Networks", Energy Policy 36, 704-713.

Severinov, S. (2008): "The Value of Information and Optimal Organization", RAND Journal of Economics 39, 238-265.

Yamashita, T. (2010): "Mechanism Games with Multiple Principals and Three or More Agents", Econometrica 78, 791-801. 